Aus der Klinik und Poliklinik für Dermatologie und Allergologie

Ludwig-Maximilians-Universität München

Direktor: Prof. Dr. med. Dr. h.c. mult. Thomas Ruzicka

\author{
Habilitationsschrift
}

zum Thema

\title{
Humane Papillomaviren (HPV) -
}

\section{Epidemiologie, Diagnostik und Therapie}

\author{
vorgelegt von
}

Dr. med. Markus Reinholz

2017

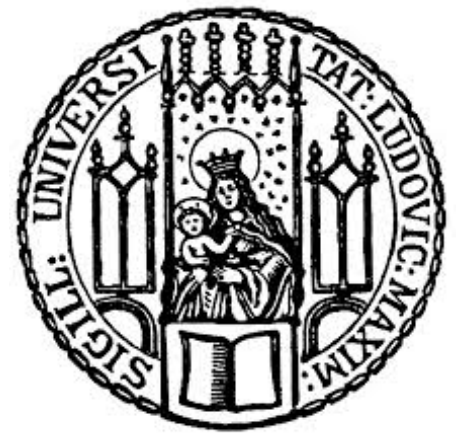




\section{INHALTSVERZEICHNIS}

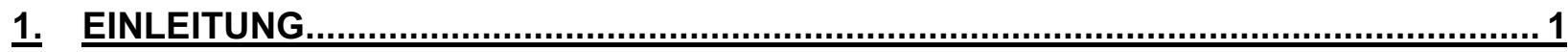

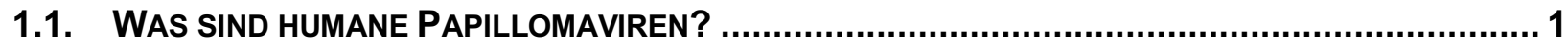

1.2. WeLChE BEDEUTUNG HABEN HPV-INFEKTIONEN? ................................................... 2

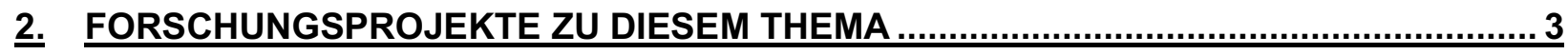

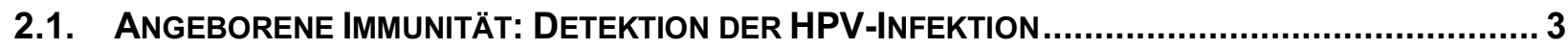

2.1.1. FRAGESTELLUNG: ERFOLGT EINE IMMUNAKTIVIERUNG DURCH HPV IN KERATINOZYTEN?.5

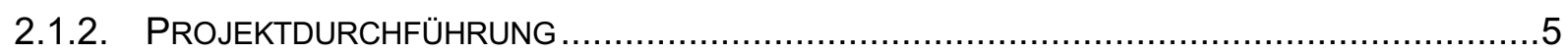

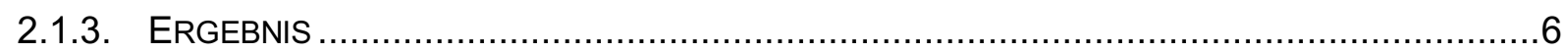

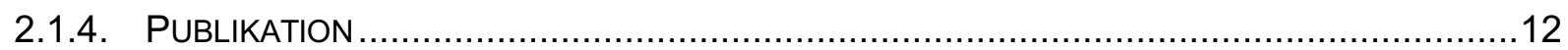

2.2. UNTERSUCHUNG VON HPV-LÄSIONEN IM ANOGENITALBEREICH MIT KLASSIFIZIERUNG UND

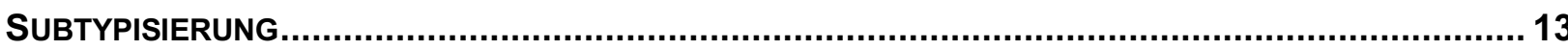

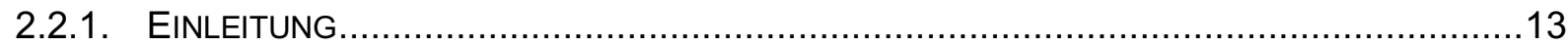

2.2.2. FRAGESTELLUNG: WELCHE SENSITIVITÄT ERREICHT DAS ANALKREBSSCREENING IN BEZUG AUF DYSPLASIEGRAD UND HPV-SUBTYPEN IM VERGLEICH ZU KONVENTIONELLER

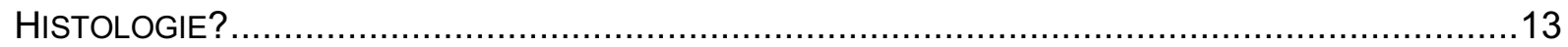

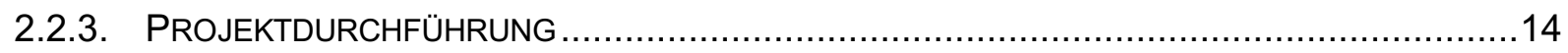

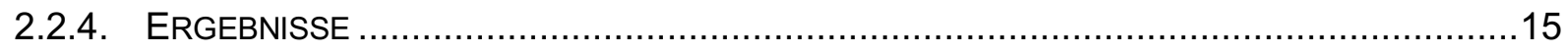

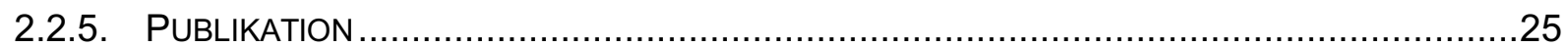

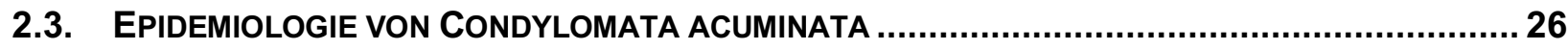

2.3.1. Fragestellung: Welche Risikofaktoren Bestehen? Ziel: Charakterisierung

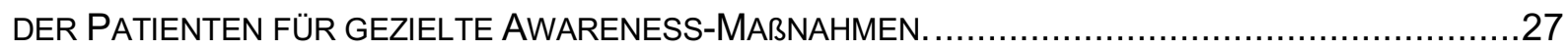

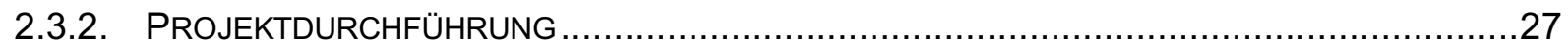

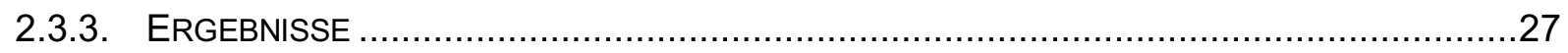

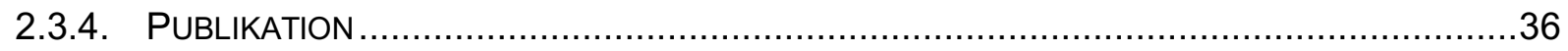

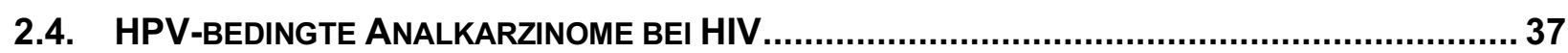

2.4.1. FRAgStelLUNG: WIE SENSITIV IST DAS DURCH DIE LEITLINIE VORGESCHLAGENE ANALKREBSSCREENING MITTELS BÜRSTENABSTRICH? IST EINE HOCHAUFLÖSENDE ANOSKOPIE

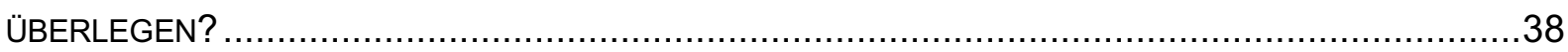

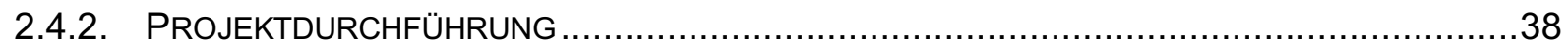

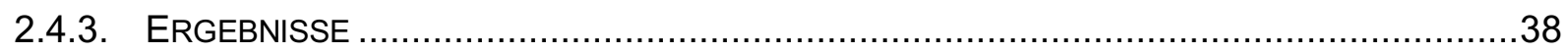

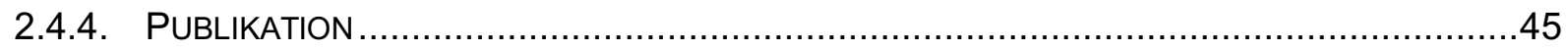

2.5. DIE ROLLE VON HPV BEI SPINOZELLULÄREN KARZINOMEN UND AKTINISCHEN KERATOSEN . 46

2.5.1. FRAGESTELLUNG: WelCHE RolLe SPIELT HPV BEI CUSCC UND AKS? .....................47

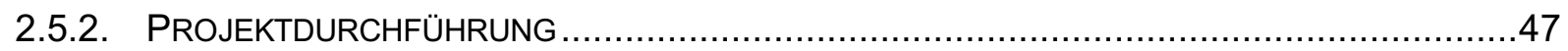

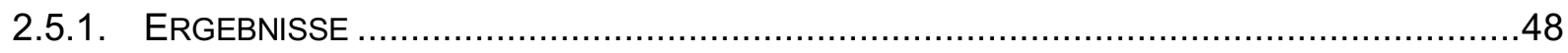

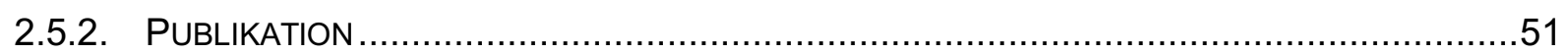

2.6. DIODENLASER IN DER BEHANDLUNG VON GENITALWARZEN..................................... 52

2.6.1. FRAGESTELLUNG: WELCHE WiRKSAMKEIT hat DER DiODENLASER IN DER BEHANDUNG

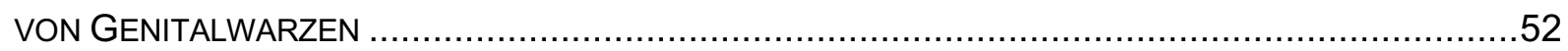

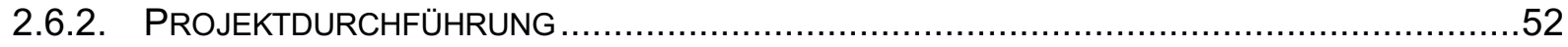




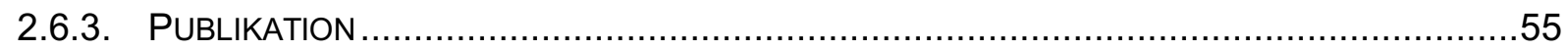

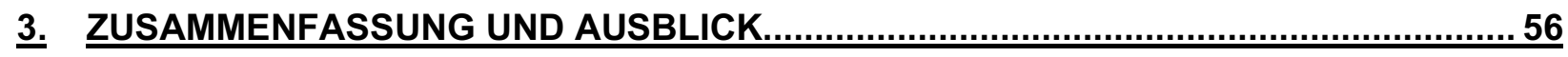

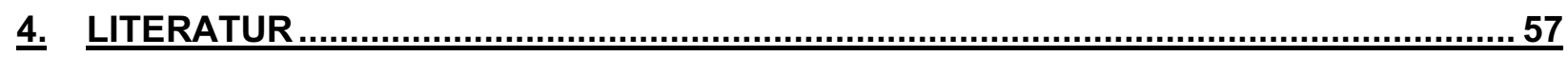

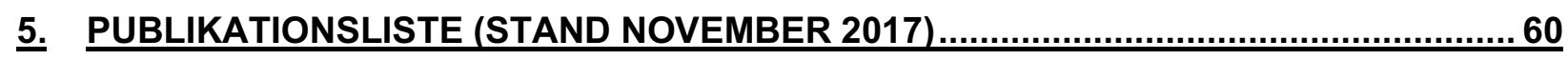

5.1. ORIGINALARBEITEN ALS ERST- ODER LETZTAUTOR................................................. 60

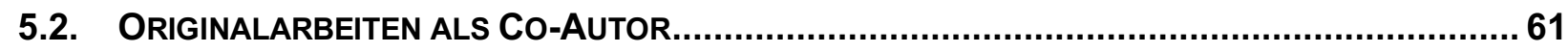

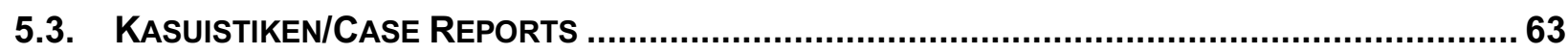

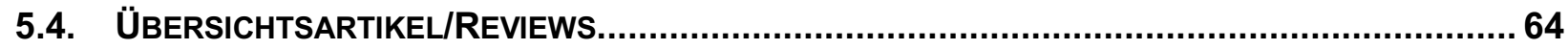

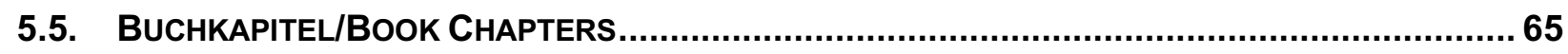

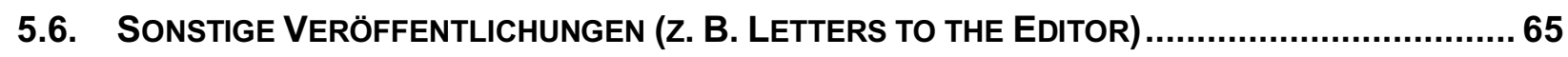

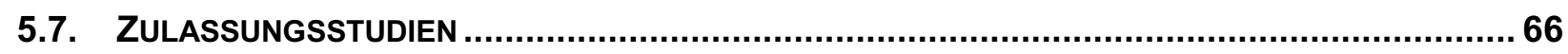

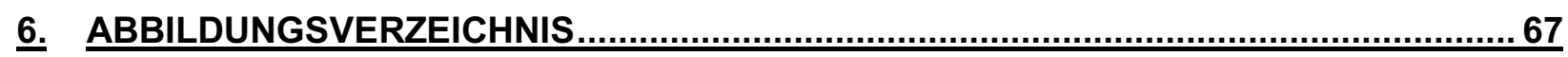

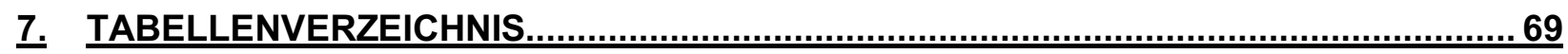

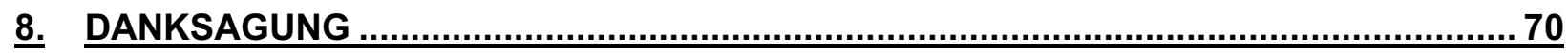

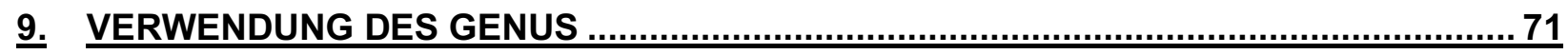

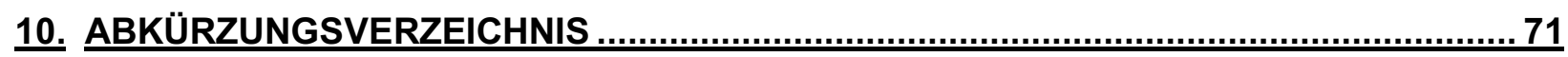





\section{Einleitung}

\subsection{Was sind humane Papillomaviren?}

Humane Papillomaviren (HPV) sind doppelsträngige DNA (dsDNA) Viren, die in mehr als 180 Subtypen differenziert werden können. Es können fünf Gattungen alpha ( $\alpha)$, beta $(\beta)$, gamma $(\gamma)$, mu $(\mu)$ und nu $(v)$ unterschieden werden [12].

Alpha-HPV sind genitale oder mukosale HPV-Typen und die größte und häufigste Gruppe von HPV. Über 40 alpha-HPV-Typen können die Anogenitalregion infizieren.

Klinisch gängiger ist die HPV-Klassifikation der alpha-HPV-Typen nach dem jeweiligen Risikopotential, Neoplasien zu erzeugen. Hierbei werden die HPV-Subtypen in niedrigRisiko (low-risk, Ir, z. B. 6, 11) und hoch-Risiko (high-risk, hr, z. B. 16, 18) eingeteilt [12, 14].

Niedrig-Risiko (Ir) Subtypen sind vorrangig mit gutartigen Genitalwarzen und einer Papillomatose der oberen Atemwege assoziiert, wohingegen hr-Viren zu intraepithelialen Neoplasien führen können und bei chronisch bestehender Infektion zu Plattenepithelkarzinomen führen können [11, 15, 22, 25].

Die weitest verbreiteten Ir-Viren sind HPV 6 und 11. HPV 16 und 18 stellen die häufigsten hr-Viren dar. Diese sind insbesondere bei der Entstehung des Zervixkarzinoms und dessen Vorstufen (CIN) beteiligt [14]. Sie können jedoch auch andere Neoplasien im Infektionsmodell und Virusreplikation von HPV nach Graham et al. [26] anogenitalen (AIN, PIN, VIN)

Bereich auslösen [33].

Es wird die Basalzellschicht der Epidermis mit dem Virus infiziert. Die Replikation des Virus erfolgt parallel mit der Differenzierung der Keratinozyten (Abbildung 1). 


\subsection{Welche Bedeutung haben HPV-Infektionen?}

HPV-Infektionen stellen die mit Abstand weltweit häufigste sexuell übertragbare, virale Erkrankung dar [43]. Sie sind maßgeblich an der Entstehung von Gebärmutterhalskrebs, anogenitalen Karzinomen sowie Oropharynxkarzinomen beteiligt [57].

Trotz der weltweiten Häufigkeit der Infektion ist jedoch wenig über die Epidemiologie in den jeweiligen Ländern der Welt und die genaue Pathogenese bekannt. Weiterhin gibt es nur begrenzte Daten zu neuen therapeutischen Ansätzen. Die im Jahr 2013 publizierte Leitlinie zum Screening auf anale Dysplasien bei HIV-Patienten stell den ersten Schritt in Richtung erhöhter Krankheits-Awareness dar, deren methodische Ansätze es jedoch zu überprüfen gilt.

In dieser Habilitationsschrift solten die Epidemiologie der HPV-Infektion, Pathomechanismen der Erkrankung, die Sensitivität von Screeningmethoden als auch therapeutische Ansätze genauer untersucht werden. Das Ziel dieser Arbeit war es, durch verschiedene Betrachtungsweisen und Untersuchungen aus unterschiedlichen Ansätzen, ein besseres Verständnis der Erkrankung und eine Verbesserung der Behandlung für die Patienten zu erreichen. Damit soll perspektivisch auch eine Senkung der Gesamtprävalenz bewirkt werden. 


\section{Forschungsprojekte zu diesem Thema}

\subsection{Angeborene Immunität: Detektion der HPV-Infektion}

Das angeborene Immunsystem ist nicht vollständig unspezifisch, wie ursprünglich angenommen. Es ist in der Lage zwischen „selbst“ und einer Reihe von Pathogenen zu unterscheiden. Es erkennt Mikroorganismen durch eine begrenzte Anzahl an genetischdeterminierten, sogenannten „pattern-recognition receptors“ (PRR). Dies ist der große Unterschied zu dem umfangreichen und variablen Repertoire an rearrangierten Rezeptoren, die vom erworbenen Immunsystem exprimiert werden [45, 50, 52, 59].

PRRs besitzen diverse gemeinsame Charakteristika. PRRs erkennen mikrobielle Bestandteile, sogenannte „pathogen-associated molecular patterns“ (PAMPs), welche unabdingbar für das Überleben von Organismen sind und daher einer evolutionären Konservierung in diesen unterliegen. Des Weiteren werden PRRs konstitutiv im Wirt exprimiert und erkennen die Pathogene unabhängig von der Zellzyklus-Phase. Außerdem sind PRRs in der nicht-klonischen Keimbahn kodiert und werden auf allen Zellen eines bestimmten Typs exprimiert. Zudem sind sie unabhängig vom immunologischen Gedächtnis [34, 45, 50, 52, 59].

Verschiedene PRRs reagieren auf jeweils bestimmte PAMPs, zeigen verschiedene Expressionsmuster, aktivieren spezifische Signalwege und führen zu antipathogenen Immunantworten. Diese Basis, welcher die angeborene Immunerkennung unterliegt, ist hoch konserviert zwischen den Spezies - von Pflanzen über Insekten bis zu den Säugetieren [34].

Einen dieser Detektionsmechanismen stellt das Inflammasom dar. Dabei handelt es sich um ein Protein-Oligomer, welches aus Caspase-1, PYCARD, NALP und in einigen Fällen Caspase- 5 besteht (auch als Caspase-11 oder ICH-3 bekannt). Es wird in Zellen der myeloischen Reihe, aber auch anderen Zellen wie Keratinozyten, exprimiert und ist Teil des angeborenen Immunsystems. 
Diese Abbildung ist aus urheberrechtlichen Gründen nicht in der Habilitationsschrift enthalten. Sie lässt sich jedoch über untenstehende Publikation direkt über den

Verlag aufrufen.

Abbildung 2 - Schematischer Aufbau des Inflammasoms

Schematischer Aufbau des Inflammasoms aus Eitel et al. [17]

Der exakte Inflammasom-Aufbau ist vom Aktivator, welcher zur InflammasomAssemblierung führt, abhängig. Beispielsweise führt dsDNA zur Konstitution einer anderen Inflammasom-Variante als etwa kristalline Strukturen (z. B. CholesterinKristalle) [34] (Abbildung 2). Diese Proteinbausteine sind in der Lage, sich neu zu formieren und in eine gemeinsame, funktionelle Struktur zu oligomerisieren (Inflammasom), welche dann in der Lage ist, Caspase-1 mit einer darauffolgenden Entzündungskaskade zu aktivieren. Hierbei spielen die Zytokine IL-1 $\beta$ und IL-18 eine zentrale Rolle. Dieser Multiproteinkomplex wurde Inflammasom benannt. Das Inflammasom ist für die Initiierung von Entzündungskaskaden verantwortlich und kann weiterhin Pyroptose induzieren, eine Variante des programmierten Zelltods in Abgrenzung zur Apoptose [34, 48]. Im Gegensatz zur Apoptose wird bei Pyroptose das Enzym Caspase-1 benötigt [20]. Caspase-1 wird wie bereits zuvor erwähnt im Rahmen der Inflammasom-Aktivierung katalytisch aktiviert und führt dann zum kontrollierten Zelltod [19].

Diese Ligand-Rezeptor-Bindungen können sich entweder auf Membranoberflächen, wie beispielsweise bei Toll-like Rezeptoren (TLRs) und C-Typ-Lektin-Rezeptoren (CTLs), oder innerhalb des Zytosols, z. B. bei NOD-like-Rezeptoren (NLRs) und RIG-I-likeRezeptoren (RLRs), abspielen. Im Jahr 2002 wurde zum ersten Mal von Martinen et al. über eine Untergruppe von NLRs, den sogenannten NLRP1, berichtet [56]. Erst später wurden weitere NLR-Untereinheiten entdeckt, wie das NLRP3 und NLRC4. Weiterhin wurde ein Inflammasom der PYHIN (pyrin and HIN-domain-containing protein)-Familie, das sogenannte AIM2-Inflammasom (absent in melanoma-2) charakterisiert, welches durch zytosolische dsDNA aktiviert wird [29]. 
Zusammenfassend kann man feststellen, dass das bessere Verständnis der initialen Infektion und der Aktivierung der angeborenen Immunantwort möglicherweise zur Entwicklung neuer Strategien für die Prävention und Behandlung von HPV-Infektionen führt.

\subsubsection{Fragestellung: Erfolgt eine Immunaktivierung durch HPV in Keratinozyten?}

Nach einer initialen Infektion eradiziert vermutlich ein Großteil der infizierten Patienten HPV. Die Persistenz bei Patienten kann möglicherweise durch eine nicht adäquate Immunantwort der Keratinozyten bedingt sein. Da es sich bei HPV um dsDNA-Viren handelt, spielen an zentraler Stelle der angeborenen Immunität möglicherweise die Rezeptoren (TLR9, AIM2 und IFI16) zur Detektion von fremder dsDNA eine wesentliche Rolle bei der initialen Immunantwort [34, 45, 50, 59]. Die Untersuchung der Detektionsmechanismen führt daher zu einem verbesserten Verständnis der Pathogenese.

\subsubsection{Projektdurchführung}

Zur Untersuchung dieser Hypothese wurden zunächst in-vitro-Untersuchungen mit primären Keratinozyten (NHEKs) durchgeführt. Zusätzlich wurde im Zellkulturmodell ein Mikromilieu simuliert, welches dem einer akuten HPV-Infektion ähnelte.

Es sollte getestet werden, inwieweit HPV-16-DNA intrazellulär prozessiert und detektiert wird sowie welche antiviralen Signalkaskaden bereits durch das angeborene Immunsystem aktiviert werden.

Zur Detektion von dsDNA lassen sich primär drei Rezeptoren identifizieren: TLR9 (tolllike Rezeptor 9), das AIM2-Inflammasom, und das gamma-interferon-inducible protein IFI16. Hierbei fokussierten wir uns auf die zytosolischen Sensoren AIM2 und IFI16, die für die Detektion von Fremd-dsDNA eine entscheidende Rolle spielen. Die beteiligten Signalwege und Koaktivatoren sollten durch entsprechende siRNAs charakterisiert werden. Die Aktivierung sollte mittels der Freisetzung der Schlüsselzytokine des jeweiligen Signalwegs (IL-1 $\beta$ als auch IFN- $\beta$ ) durch ELISA gemessen werden.

Weiterhin sollten HPV-positive menschliche Hautläsionen auf Expression mittels der in den letzten Jahren entdeckten DNA-Sensoren AIM2 und IFI16 untersucht werden. CISH (chromogenic in-situ hybridization) Färbungen sollten zytosolische DNA nachweisen. Darüber hinaus wurden in diesen Hautbiopsien immunhistochemische Nachweise von 
aktivem IL-1 $\beta$ als auch prozessierter Caspase-1 sowie downstream-Mediatoren der jeweiligen Signalkaskade untersucht.

In weiterführenden in-vitro-Studien wurde die HPV 16 getriggerte Freisetzung von IL-1 $\beta$ und IL-18 mittels AIM2-Inflammasom in primären humanen Keratinozyten untersucht.

\subsubsection{Ergebnis}

In dieser Studie wurden die Mechanismen der HPV-induzierten Immunantwort in Keratinozyten untersucht. Die Bindung von viraler DNA an das AIM2-Inflammasom führte zu dessen Aktivierung mit konsekutiver Freisetzung von IL-1 $\beta$, wohingegen IFI16Aktivierung eine IFN- $\beta$-Freisetzung bewirkte [45].

Mittels Immunhistochemie konnten AIM2 und IFI16 - zwei in den letzten Jahren beschriebenen, zytosolischen DNA-Rezeptoren - in HPV-positiven Hautläsionen nachgewiesen werden (Abbildung 3 und 4). 
Diese Abbildung ist aus urheberrechtlichen Gründen nicht in der Habilitationsschrift enthalten. Sie lässt sich jedoch über untenstehende Publikation direkt über den Verlag aufrufen.

Abbildung 3 - AlM2, IL-1 $\beta$ und Caspase-1 in AIN 3 bei HIV-positiven Patienten

Eine AIM2-Proteinexpression (a) wurde mittels Immunhistochemie in Biopsien aus perianaler Haut von Patienten mit analer intraepithelialer Neoplasie (AIN) nachgewiesen bei positivem HPV-16- / HPV-18-Befund.

Prozessierte Caspase-1 und prozessiertes IL-1 in Proteinfärbungen zeigten Inflammasom-Aktivierung in Keratinozyten bei einer kutanen HPV-Infektion (c, e) an. AIM2, prozessierte Caspase-1 und prozessiertes IL-1 13 waren negativ in der Kontrolle und gesunder Haut b, d, f. Isotyp-Kontrollfärbungen waren negativ (Daten nicht gezeigt). Abbildung aus Reinholz et al. \{Reinholz, 2013 \#15\}. 
Abbildung 4 - Expression von IFI16 in HPV-infizierter Haut

Zusätzlich wurde IFI16 in HPV 16/18 positivem Gewebe mit einem sowohl zytosolischen als nukleärem Färbemuster nachgewiesen ( $a, b$, durch Pfeile markiert). In der nichtbetroffenen Kontrollhaut war IFI16 auch mit einem nukleären Färbemuster exprimiert (c), wohingegen AIM2 nicht nachgewiesen wurde (Abbildung $3 b$ ). Isotyp Poly IgG war in der nichtbetroffenen Haut negativ (d). Abbildung aus Reinholz et al. \{Reinholz, 2013 \#15\}.
Diese Abbildung ist aus urheberrechtlichen Gründen nicht in der Habilitationsschrift enthalten. Sie lässt sich jedoch über untenstehende Publikation direkt über den Verlag aufrufen.

$\mathrm{CISH}$ Färbungen konnten weiterhin bestätigen, dass sich HPV-16-DNA in den untersuchten Biopsien zytosolisch zu finden war (Abbildung 5).

Diese Abbildung ist aus urheberrechtlichen Gründen nicht in der Habilitationsschrift enthalten. Sie lässt sich jedoch über untenstehende Publikation direkt über den

Verlag aufrufen.

\section{Abbildung 5 - HPV 16 Nachweis mittels $\mathrm{CISH}$}

HPV-16- bzw. HPV-18-DNA war sowohl nukleär als zytosolisch mittels HPV-16/18-spezifischer CISH in AIN nachweisbar. Weiterhin wurde in den Hautproben mittels PCR bereits zuvor ein HPV-16/18-Nachweis geführt. Die Pfeile zeigen auf das rötlich-pinkfarbene zytosolische Färbemuster. Dieses entstand als Nachweis des PCR-Produkts und zeigte HPV-16-DNA an. Je intensivier die Rotfärbung desto mehr HPV-16-DNA war vorhanden. Abbildung aus Reinholz et al. \{Reinholz, $2013 \# 15\}$.

Außerdem wurde AIM2, aktiviertes IL-1 $\beta$ und prozessierte Caspase-1 nachgewiesen (Abbildung 3). Dies führte zur Annahme, dass der Inflammasom-Signalweg durch die virale DNA aktiviert wurde (Abbildung 3). Der Nachweis von HPV-DNA im Zytosol erfolgte vor allem in weiter apikal differenzierten Keratinozyten (Abbildung 5). Die 
Virionbildung, die parallel mit der Keratinozytendifferenzierung abläuft, führte vermutlich auch zu HPV-DNA im Zytosol, welche dann durch das AIM2-Inflammasom erkannt wurde.

In nachfolgenden in-vitro-Studien konnte gezeigt werden, dass HPV-16-DNA in normalen humanen Keratinozyten (NHEK) zur Freisetzung von IL-1 $\beta$ und IL-18 über das AIM2-Inflammasom führt (Abbildung 6, 8). Obwohl HPV-DNA nicht zur Induktion von IFN- $\beta$ führte, wurde eine Freisetzung beobachtet, wenn AIM2 mittels siRNA blockiert wurde.

Diese Abbildung ist aus urheberrechtlichen Gründen nicht in der Habilitationsschrift enthalten. Sie lässt sich jedoch über untenstehende Publikation direkt über den Verlag aufrufen.

Zytosolische HPV-16-DNA führte zur Freisetzung von IL1- $\beta$ mittels AIM2-Inflammasom in humanen Keratinozyten. (A) Primäre humane Keratinozyten wurden entweder mit negativer Kontrolle (keine DNA) bzW. HPV-16-DNA transfiziert. In Kontrollexperimenten wurde die HPV-16-DNA vor Transfektion verdaut. IL-1 $\beta$ Sekretion wurde in Zellkulturüberständen nach $24 \mathrm{~h}$ mittels ELISA nachgewiesen. (B) Keratinozyten wurden mit verschiedenen siRNAs (AIM2, ASC, Caspase-1) oder einer nicht-zielgerichteten siRNA vor Behandlung mit HPV-16-DNA transfiziert. Die IL-1 $\beta$ Freisetzung wurde nach 24 Stunden bestimmt. Alle Daten wurden als Durchschnittswert mit Standardabweichung dargestellt $\left(n=3 ;{ }^{* * *} p \backslash 0.001\right.$, Student's t test). (C, D) CFP-ASC-Makrophagen wurden mit HPV-16-DNA (D) oder Kontrolle (keine DNA) (C) transfiziert und deren Fluoreszenz nach 24 Stunden untersucht. Die Pfeile zeigen die Ausbildung von ASC-enthaltenden Komplexen (ASC ist ein Bestanteil des Inflammasom), welche die Inflammasom-Aktivierung anzeigen. Abbildung aus Reinholz et al. \{Reinholz, $2013 \# 15\}$. 
Die Blockade von IFI16 führte hingegen zu einer erhöhten HPV-16-DNA-induzierten IL1$\beta$ Freisetzung, nicht jedoch zu einer vermehrten IL-18 Freisetzung. Bei der AIM2Blockade mittels siRNA kam es jedoch nicht zu einer verstärkten Aktivierung des IFI16Signalwegs. Dies suggerierte eine Interaktion zwischen IFI16 und AIM2 in der Immunantwort auf HPV-DNA und eine einseitige Beeinflussbarkeit der Signalkaskaden durch IFI16-Blockade (Abbildung 7, 8).

Diese Abbildung ist aus urheberrechtlichen Gründen nicht in der Habilitationsschrift enthalten. Die Abbildung ist in der Autorenversion enthalten und kann über den Autor eingesehen werden.

Abbildung 7 - Schema: Mögliche Interaktion zwischen dem IFI16- und AIM2-Signalweg

Die Blockade des AIM2-Signalwegs mittels siRNA führte vermutlich zu einer stärkeren Aktivierung des IFI16-Signalwegs. Dahingegen hatte die Blockade des IFI16-Signalwegs mittels siRNA keinen nachweisbaren Einfluss auf den AIM2-Signalweg. Eigene Abbildung von Dr. M. Reinholz. 
Diese Abbildung ist aus urheberrechtlichen Gründen nicht in der Habilitationsschrift enthalten. Sie lässt sich jedoch über untenstehende Publikation direkt über den Verlag aufrufen.

Abbildung 8 - Interaktion IFI16 und AIM2-Signalweg durch HPV-DNA

Die Inhibition von IFI16 in Keratinozyten führte zur verstärkten, der durch HPV-DNA bedingten, IL-1 $\beta$ Freisetzung aus Keratinozyten. Keratinozyten wurde mit siRNA von AIM2, IFI16 oder einer Kontroll-siRNA transfiziert. Die Zellen wurden folglich entweder mit HPV-16-DNA oder mit einer Kontrolle transfiziert. IL-1 $\beta-(A)$, IFN- $\beta$ - (C) und IL-18-Freisetzung (E) wurde nach 24 Stunden gemessen. In Parallelexperimenten wurden humane Keratinozyten mit derselben siRNA transfiziert und im Anschluss mit einer synthetischen dsDNA (poly(dA:dT)). IL-1 $\beta$ (B), IFN- $\beta$ (D) und IL-18 (F) wurden nach 24 Stunden gemessen. Die Daten zeigten Mittelwerte mit Standardabweichung $\left(n=3 ;{ }^{* * *} p \backslash 0.001,{ }^{* *} p \backslash 0.01,{ }^{*} p \backslash 0.05\right.$, Student's t test). Abbildung aus Reinholz et al. \{Reinholz, 2013 \#15\}. 
Zusammenfassend konnte gezeigt werden, dass Komponenten des AIM2Inflammasoms in AIN nachweisbar waren. Weiterhin konnten die prozessierten und damit aktiven Signalmoleküle (IL-1 $\beta$, IL-18) des Inflammasoms nachgewiesen werden. Außerdem wurde IFI16 in AIN-Läsionen nachgewiesen. Eine CISH-Analyse konnte zeigen, dass sich zytosolische HPV-16-DNA nachweisen ließ. Dies ist sowohl obligate Voraussetzung für die Aktivierung des AIM2-Inflammasoms, als auch für IFI16.

In vitro konnte bei Stimulation des AIM2-Inflammasom eine IL-1 $\beta$ und IL-18-Freisetzung nachgewiesen werden. Des Weiteren konnte bei IFI16-Aktivierung eine IFN- $\beta$ Freisetzung gezeigt werden. Die beiden Signalwege schienen zumindest einseitig miteinander verknüpft zu sein. Denn die Inhibition von IFI16 führte zu einer vermehrten Freisetzung von IL-1 $\beta$, nicht jedoch von IL-18. Eine Inhibition von AIM2 führte jedoch zu keiner Änderung der Freisetzung von IFN- $\beta$ (Abbildung 7, 8).

In Summe konnten neue Erkenntnisse bezüglich der HPV-induzierten angeborenen Immunantwort gewonnen werden. Durch ein besseres Verständnis der HPV-induzierten Inflammasom-Aktivierung können möglicherweise neue Strategien zur Prävention und der Behandlung der HPV-Infektion gefunden werden.

\subsubsection{Publikation}

Reinholz M, Kawakami Y, Salzer S, Kreuter A, Dombrowski Y, Koglin S, Kresse S, Ruzicka T, Schauber J. HPV16 activates the AIM2 inflammasome in keratinocytes. Arch Dermatol Res. 2013 Oct;305(8):723-32. IF (2013): 2.270 


\subsection{Untersuchung von HPV-Läsionen im Anogenitalbereich mit Klassifizierung und Subtypisierung}

\subsubsection{Einleitung}

Durch die verbesserte antiretrovirale Therapie (ART) haben sich in der Betreuung HIVpositiver Patienten neue Herausforderungen ergeben [18]. Durch die verbesserte Prognose rücken nun andere Komorbiditäten der Patienten in den Fokus der HIVBehandler. Mittlerweile stellen Krebserkrankungen bei HIV-Infizierten eine der häufigsten Todesursachen dar [18]. Nicht AIDS-definierende Erkrankungen nehmen gegenüber AIDS-definierenden Neoplasien deutlich zu [18]. Hierzu gehören neben HodgkinLymphomen und Bronchialkarzinomen vor allem die Analkarzinome. Diese Neoplasie wird analog zum Zervixkarzinom durch die Infektion mit humanen Papillomaviren (HPV, v. a. Typen 16 und 18) hervorgerufen [7, 18, 24, 38]. Eine ansteigende Inzidenz des Analkarzinoms und seiner Vorläufererkrankungen ist bei HIV-Infizierten trotz ART zu beobachten [23, 35, 37, 49]. Dies führte zur Entwicklung der AWMF-Leitlinie „Anale Dysplasien und Analkarzinome bei HIV-Infizierten: Prävention, Diagnostik, Therapie“ [18].

Zwischen einer persistierenden HPV-Infektion und der Entwicklung eines Analkarzinoms können Jahre vergehen [18]. Aufgrund der klinischen Bedeutung der anogenitalen intraepithelialen Dys-/Neoplasien als Vorläuferläsionen für ein Analkarzinom lässt sich die Möglichkeit zur Früherkennung und damit die Notwendigkeit für ein Screeningprogramm ableiten [1, 18, 32]. Bislang haben sich jedoch internationale Fachgesellschaften aufgrund mangelnder Evidenz noch nicht hierfür ausgesprochen [37]. Die vorliegende deutschen Leitlinie der Deutschen AIDS Gesellschaft e.V. (DAIG) gibt erstmalig Empfehlungen für das Management der anogenitalen HPV-assoziierten Läsionen bei HIV-Infizierten [18]. Eine Überprüfung der Sensitivität und möglicher weiterer diagnostischer Marker für eine Karzinomfrüherkennung hat bisher nicht stattgefunden.

\subsubsection{Fragestellung: Welche Sensitivität erreicht das Analkrebsscreening in Bezug auf} Dysplasiegrad und HPV-Subtypen im Vergleich zu konventioneller Histologie?

Besonderheiten bei HIV/HPV-Koinfizierten in der Epidemiologie und im Verlauf, sowie aktuelle Entwicklungen in der Prävention (Impfungen gegen HPV), Diagnostik (Analzytologie, hochauflösende Anoskopie) und Therapie werden in den vorhandenen Leitlinien nur teilweise berücksichtigt, obwohl es bereits zahlreiche Leitlinien zu dieser 
Thematik gibt [27, 28]. Die steigende Inzidenz des Analkarzinoms bei HIV-Infizierten macht ein abgestimmtes Vorgehen zwischen HIV-Schwerpunktbehandlern, Infektiologen, Venerologen, Dermatologen, Proktologen, Gynäkologen, Chirurgen, Gastroenterologen, Onkologen und Strahlentherapeuten sowie Histopathologen, Zytologen und Virologen erforderlich. Eine Überprüfung der in der aktuellen S2k-Leitlinie [18] empfohlenen Maßnahmen ist daher dringend angezeigt, um die Betreuung der HIVPatienten weiter zu verbessern.

\subsubsection{Projektdurchführung}

Onkogene HPV, vor allem HPV 16, sind in über $90 \%$ der Zervixneoplasien und analen intraepithelialen Neoplasien (AIN) zu finden. Eine human immunodeficiency virus (HIV)Infektion ist mit einem erhöhten Risiko für die maligne Entartung von AIN assoziiert. Im September 2013 sind daher Guidelines zur Prävention, Screening und Behandlung von AIN für Patienten, die von einer HIV-Infektion betroffen sind, von der Deutschen AIDS Gesellschaft erschienen.

In dieser Studie wurden erstmalig die Ergebnisse der HPV-Typisierung im Zusammenhang mit histologischen Ergebnissen bei den betroffenen Patienten untersucht. Insbesondere die HPV-Subtypisierung und die Identifikation neuer Screening-Parameter standen im Zentrum dieser retrospektiven Studie. Eine ethischrechtliche Unbedenklichkeitsbescheinigung dieser retrospektiven Analyse der Ethikkommission der LMU München lag vor (UE 112-14).

Eine Risikoanalyse der malignen Entartung bei Vorliegen bestimmter HPV-Subtypen kann möglicherweise zu einem prädiktiven Faktor für das potenzielle Entartungsrisiko werden. 


\subsubsection{Ergebnisse}

Geschlechterverteilung

Die Verteilung der Geschlechter in der untersuchten Population der Klinik und Poliklinik für Dermatologie und Venerologie der LMU betrug bei den 121 Patienten, denen eine oder mehrere Gewebeproben entnommen wurden, 14 Frauen zu 107 Männern. Dies entsprach einer prozentualen Verteilung von $88,4 \%$ Männern und 11,6 \% Frauen (Abbildung 9) (Daten Dissertation Bruno Hundsdörfer).

\section{Altersverteilung}

In den letzten Jahren wurden Verschiebungen der Altersverteilung anogenitaler Neoplasien festgestellt [18]. Da das Alter der Patienten möglicherweise mit anderen pathogenetischen Mechanismen assoziiert ist und damit zu Unterschieden führen könnte, wurde die Altersverteilung in der untersuchten Stichprobe zunächst analysiert. Bei den insgesamt 121 betrachteten Patienten betrug das mittlere Alter (Jahre \pm SD) 47,79 $\pm 14,28$ Jahre. Der jüngste Patient, der sich einer Gewebeprobenentnahme unterzog, war 24 Jahre, der älteste Patient war 87 Jahre alt. Alle Altersangaben und Alterseinteilungen bezogen sich auf das Bezugsdatum 1. Januar 2017 (Abbildung 10) (Daten Dissertation Bruno Hundsdörfer).
Diese Abbildung ist aus urheberrechtlichen

Gründen nicht in der Habilitationsschrift enthalten. Die Abbildung ist in der Autorenversion enthalten und kann über den Autor eingesehen werden.

Gesamtanzahl der untersuchten Proben der Kohorte $(n=121)$ Davon stammten $11,6 \%$ der Proben von weiblichen und $88,4 \%$ von männliche Patienten. 


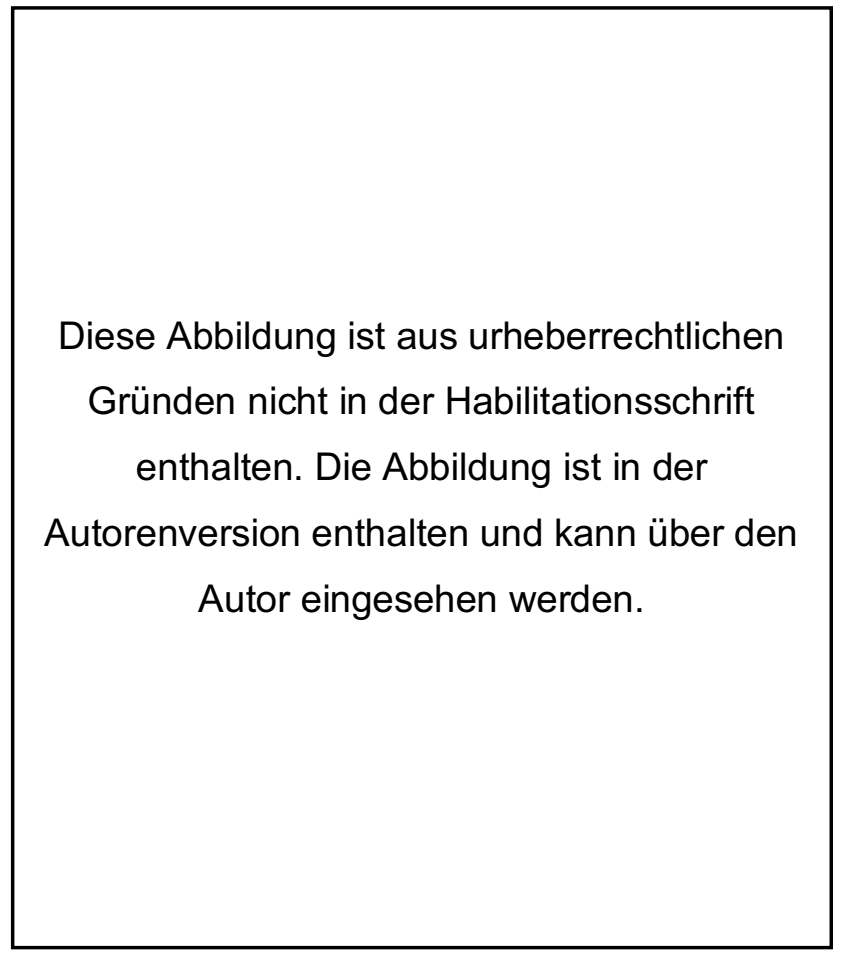

Abbildung 10 - Altersverteilung der untersuchten HIV-Patienten

Bei den insgesamt 121 betrachteten Patienten betrug das mittlere Alter (Jahre $\pm S D$ ) 47,79 $\pm 14,28$ Jahre. Der jüngste Patient, der sich einer Gewebeprobenentnahme unterzog, war 24 Jahre alt. Der älteste Patient war 87 Jahre alt. Alle Altersangaben und Alterseinteilungen bezogen sich auf das Bezugsdatum 1. Januar 2017.

In der Gruppe der Gewebeproben mit reinen Ir-HPV lag der Altersdurchschnitt mit 42,9 Jahren (SD $\pm 12,5$ ) etwas niedriger als in der Gruppe mit hr-Gewebeproben mit 46,7 Jahren (SD $\pm 14,9$ ). In beiden Gruppen war das Alter leicht rechtsschief verteilt und der Kolmogorov-Smirnov-Test lieferte jeweils ein signifikantes Ergebnis $(P<0,01)$, so dass von relevanten Abweichungen von einer Normalverteilung auszugehen war. Für einen Vergleich der beiden Gruppen hinsichtlich des Alters (low-risk: Median = 41,2; high-risk: Median = 43,5) wurde deshalb der Mann-Whitney-U-Test verwendet. Im Rahmen dieses Tests konnten keine signifikanten Unterschiede zwischen den beiden Gruppen festgestellt werden $(z=1,49, P=0,136)$ (Abbildung 11) (Daten Dissertation Bruno Hundsdörfer).

\section{Verteilung der HIV-Infektion in der Kohorte}

Die untersuchte Kohorte bestand aus insgesamt 121 Proben, die von 107 männlichen und 14 weiblichen Patienten stammten. Von den männlichen Patienten lag der Anteil an nachweislich an HIV Erkrankten bei $55,1 \%$, bei den weiblichen Patienten bei 21,4 \%. Bei 24,3\% der männlichen Patienten und 28,6\% der weiblichen Patienten war der HIVStatus unbekannt. $24,3 \%$ der Patienten und $50 \%$ der Patientinnen waren nachweislich HIV-negativ (Abbildung 11) (Daten Dissertation Bruno Hundsdörfer). 
Diese Abbildung ist aus urheberrechtlichen Gründen nicht in der Habilitationsschrift enthalten. Die Abbildung ist in der Autorenversion enthalten und kann über den Autor eingesehen werden.

\section{Abbildung 11 - Verteilung der HIV-Infektion in der Kohorte}

Die untersuchte Stichprobe ließ sich auch im Hinblick auf das Geschlecht und auf das Vorliegen einer HIV-Erkrankung einteilen. Die untersuchte Kohorte bestand aus insgesamt 121 Proben, die von 107 männlichen und 14 weiblichen Patienten stammten. Von den männlichen Patienten lag der Anteil an nachweislich an HIV Erkrankten bei $55,1 \%$ und bei $21,4 \%$ bei den weiblichen Patienten. Bei 24,3\% der männlichen Patienten und 28,6\% der weiblichen Patienten war der HIV-Status unbekannt. 24,3\% der Patienten und 50\% der Patientinnen waren nachweislich HIV-negativ (Abbildung 11).

\section{Gewebeproben}

Insgesamt wurden an 121 Patienten 210 Gewebeproben entnommen. Bei 60 (49,6\%) Patienten konnte lediglich eine Gewebeprobe entnommen werden, bei 29 (24,0\%) Patienten zwei Proben und bei 18 (14,9\%) Patienten drei Proben. Vier Gewebeproben wurden bei drei (2,5 \%) Patienten und fünf Gewebeproben bei einem $(0,8 \%)$ Patienten entnommen. Die gewonnenen Gewebeproben wurden hinsichtlich des Läsionsortes deskriptiv ausgewertet und nach entsprechender Geschlechterverteilung sortiert. Somit erhielt man einen Überblick über die Verteilung der Stichprobe (Abbildung 12). (Daten Dissertation Bruno Hundsdörfer) 
Diese Abbildung ist aus urheberrechtlichen Gründen nicht in der Habilitationsschrift enthalten.

Die Abbildung ist in der Autorenversion enthalten und kann über den Autor eingesehen werden.

Abbildung 12 - Lokalisation der Gewebeproben

Insgesamt wurden an 121 Patienten 210 Gewebeproben entnommen. Bei 60 (49,6\%) Patienten konnte lediglich eine Gewebeprobe entnommen werden, bei 29 (24,0\%) Patienten zwei Proben und bei 18 (14,9\%) Patienten drei Proben. Vier Gewebeproben wurden bei drei (2,5\%) Patienten und fünf Gewebeproben bei einem (0,8 \%) Patienten entnommen. Die gewonnenen Gewebeproben wurden hinsichtlich des Läsionsortes deskriptiv ausgewertet und nach entsprechender Geschlechterverteilung sortiert.

\section{Histologische Klassifizierung}

8 der 210 Proben waren histologisch als unauffällig befundet worden und dienten als Kontrollgruppe. Die zweite Gruppe bestand aus 114 Gewebeproben, die eine intraepitheliale Neoplasie aufwiesen, wovon 15 einen Grad 1, 16 einen Grad 2 und 83 Proben einen Grad 3 hatten. In der Gruppe der intraepithelialen Neoplasien waren sowohl anale und vulväre als auch Gewebeproben des Penis enthalten. 88 der 210 Proben waren als Condylomata acuminata histologisch klassifiziert worden und bildeten die dritte Gruppe (Abbildung 13). (Daten Dissertation Bruno Hundsdörfer) 
Diese Abbildung ist aus urheberrechtlichen Gründen nicht in der Habilitationsschrift enthalten.

Die Abbildung ist in der Autorenversion enthalten und kann über den Autor eingesehen werden.

Abbildung 13 - Histologische Klassifizierung

114 Gewebeproben wiesen eine intraepitheliale Neoplasie auf, wovon 15 einen Grad 1, 16 einen Grad 2 und 83 Proben einen Grad 3 hatten. In der Gruppe der intraepithelialen Neoplasien waren sowohl anale und vulväre als auch Gewebeproben des Penis enthalten. 88 der 210 Proben waren als Condylomata acuminata histologisch klassifiziert worden und bilden die dritte Gruppe. 8 der 210 Proben waren histologisch unauffällig befundet worden und dienten als Kontrollgruppe (rechts außen).

Low-risk-, high-risk-HPV und Mischinfektionsverteilung an HPV-Subtypenkombinationen

Ziel des Studiendesigns war die Gegenüberstellung von histologisch untersuchten Gewebeproben und ihre anschließende molekulargenetische Analyse zum Nachweis enthaltener HPV-Subtypen (Abbildung 13; Tabelle 1). (Daten Dissertation Bruno Hundsdörfer) 
Diese Abbildung ist aus urheberrechtlichen Gründen nicht in der Habilitationsschrift enthalten.

Die Abbildung ist in der Autorenversion enthalten und kann über den Autor eingesehen werden.

Tabelle 1 - HPV-Subtypenkombinationen in IN verschiedener Schweregrade

Nachweis und Aufschlüsselung der jeweiligen Subtypen klassifiziert nach hr und Ir, sowie der Kombination aus beiden. Als Gegenüberstellung von histologisch untersuchten Gewebeproben (Spalte) und ihre anschließende molekulargenetische Analyse zum Nachweis enthaltener HPV-Subtypen (Zeile). 
Die Gruppe der high-risk-Gewebeproben beinhaltete alle Stichproben, die mindestens einen high-risk-Subtyp und eventuell einen oder mehrere low-risk-Subtypen enthielten. In der Gruppe der low-risk-Gewebeproben befanden sich nur Stichproben mit ausschließlich low-risk-Subtypen. Es gab einen signifikanten Zusammenhang zwischen dem Vorkommen von high-risk- beziehungsweise low-risk-Typen und des Histologiebefunds (chi quadrat $\mathrm{X}(3)=44,51, \mathrm{P}<, 001 /$ exakter Test nach Fisher: $\mathrm{P}<$ 0,001). In der Gruppe IN3 war der Prozentsatz an high-risk-Typen signifikant höher als bei einem unauffälligen Befund, wie beispielsweise bei IN1/IN2 und bei Condylomata acuminata. Für Condylomata acuminata und für IN1/IN2 konnte kein Unterschied hinsichtlich des Auftretens von low-risk-Typen nachgewiesen werden. Der Effekt war mit $V=0,46$ (Cramer's V) von mittlerer Stärke. Bei 26 von 88 histologisch untersuchten Feigwarzen konnten bei der molekulargenetischen Untersuchung ein oder mehrere highrisk-Subtypen nachgewiesen werden (Abbildung 14, Tabelle 2). (Daten Dissertation Bruno Hundsdörfer)

Diese Abbildung ist aus urheberrechtlichen Gründen nicht in der Habilitationsschrift enthalten. Die Abbildung ist in der Autorenversion enthalten und kann über den Autor eingesehen werden.

Abbildung 14 - Histologie im Vergleich zur molekulargenetischen Analyse

Die Gruppe der high-risk-Gewebeproben beinhaltete alle Stichproben, die mindestens einen high-risk-Subtyp und eventuell einen oder mehrere low-risk-Subtypen enthielten. In der Gruppe der low-risk-Gewebeproben befanden sich nur Stichproben mit ausschließlich low-risk-Subtypen. Es gab einen signifikanten Zusammenhang zwischen dem Vorkommen von high-risk- beziehungsweise low-risk-Typen und dem Histologiebefund (chi quadrat $X(3)=44,51, P<, 001 /$ exakter Test nach Fisher: $\mathrm{P}<0,001)$. 
Diese Tabelle ist aus urheberrechtlichen Gründen nicht in der Habilitationsschrift enthalten. Die Tabelle ist in der Autorenversion enthalten und kann über den Autor eingesehen werden.

Tabelle 2 - Histologie im Vergleich zur molekulargenetischen Analyse

In der Gruppe IN3 war der Prozentsatz an high-risk-Typen signifikant höher als bei einem unauffälligen Befund, wie beispielsweise bei IN1/IN2 und bei Condylomata acuminata. Für Condylomata acuminata und für IN1/IN2 konnte kein Unterschied hinsichtlich des Auftretens von low-risk-Typen nachgewiesen werden. Der Effekt war mit $V=0,46$ (Cramer's V) von mittlerer Stärke.

Begriffserklärung $\mathrm{IN}=$ =intraepitheliale Neoplasie, $\mathrm{N}=\mathrm{Anzahl}$

\section{Häufigkeitsverteilung Subtypen in Feigwarzen}

Nur die Subtypen HPV 6 oder HPV 11 kamen bei Feigwarzen mit 51,9\% überdurchschnittlich häufig vor im Vergleich zu den beiden Gruppen low-risk (IN1, IN2) und high-risk (IN3) (chi-quadrat $\mathrm{X} 2(3)=40,97, \mathrm{P}<0,001$ ). Dieser Effekt war von mittlerer bis großer Stärke $(V=0,44)$. Die Kombination von HPV 6 und HPV 11 in einer Gewebeprobe konnte nicht nachgewiesen werden. (Abbildung 15).

Diese Abbildung ist aus urheberrechtlichen Gründen nicht in der Habilitationsschrift enthalten. Die Abbildung ist in der Autorenversion enthalten und kann über den Autor eingesehen werden.

Abbildung 15 - Häufigkeitsverteilung Subtypen in Feigwarzen

Nur die Subtypen HPV 6 oder HPV 11 kamen bei Feigwarzen mit 51,9\% überdurchschnittlich häufig vor im Vergleich zu den beiden Gruppen low-risk (IN1, IN2) und high-risk (IN3) (chi-quadrat X2(3) = 40,97, P < 0,001). Dieser Effekt war von mittlerer bis großer Stärke $(V=0,44)$. Die Kombination von HPV 6 und HPV 11 in einer Gewebeprobe konnte nicht nachgewiesen werden. 
Diese Tabelle ist aus urheberrechtlichen Gründen nicht in der Habilitationsschrift enthalten. Die Tabelle ist in der Autorenversion enthalten und kann über den Autor eingesehen werden.

Tabelle 3 - Häufigkeitsverteilung Subtypen in Feigwarzen

Anmerkung: Die hochgestellten Buchstaben sind zeilenweise zu lesen. Unterschiedliche hochgestellte Buchstaben verweisen auf einen signifikanten Unterschied $(P<0,05$, Korrektur des Signifikanzniveaus nach Bonferroni).

Begriffserklärung IN=intraepitheliale Neoplasie, $\mathrm{N}=\mathrm{Anzahl}$

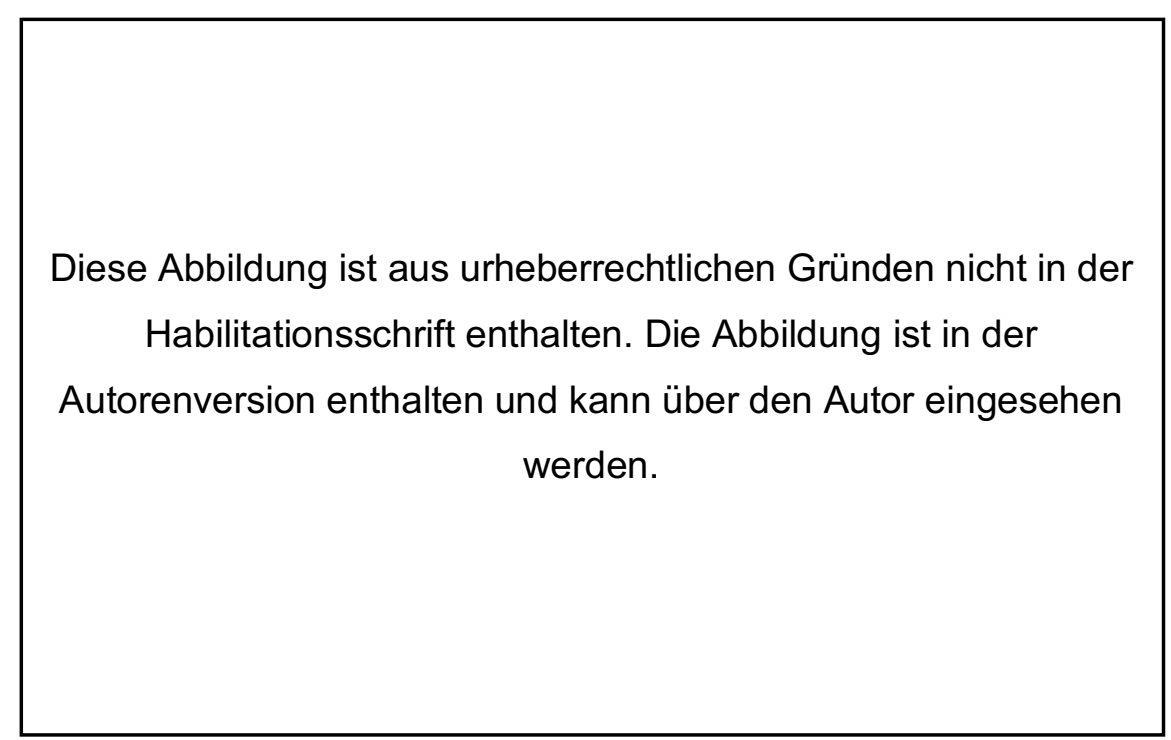

Abbildung 16 - Häufigkeitsverteilung der HPV-Subtypen in IN 1

Verteilung der HPV-Subtypen nach AIN-Grading (grün=Ir, gelb=intermediate risk/unknown, rot=hr).

Diese Abbildung ist aus urheberrechtlichen Gründen nicht in der

Habilitationsschrift enthalten. Die Abbildung ist in der

Autorenversion enthalten und kann über den Autor eingesehen

werden.

Abbildung 17 - Häufigkeitsverteilung der HPV-Subtypen in IN 2

Verteilung der HPV-Subtypen nach AIN-Grading (grün=Ir, gelb=intermediate risk/unknown, rot=hr). 
Diese Abbildung ist aus urheberrechtlichen Gründen nicht in der Habilitationsschrift enthalten. Die Abbildung ist in der Autorenversion enthalten und kann über den Autor eingesehen werden.

Abbildung 18 - Häufigkeitsverteilung der HPV-Subtypen in IN 3

Verteilung der HPV-Subtypen nach AIN-Grading (grün=Ir, gelb=intermediate risk/unknown, rot=hr).

Invasivitätsgrad und molekulargenetischer Analyse

Gruppe 2: Es gab einen signifikanten Zusammenhang zwischen dem Vorkommen von HPV 16 (aber ohne HPV 18) und den Klassifizierungen IN1 bis IN3 (X2(2) = 13,62, P = 0,001). Dieser Effekt war von mittlerer Stärke $(V=, 35)$. In der Klasse IN3 war der Prozentsatz an Gruppe 2 signifikant höher als in den beiden anderen Klassen.

Gruppe 3: Es war kein Zusammenhang zwischen dem Vorkommen von HPV 18 (ohne HPV 16) und den Tumorstadien nachweisbar (exakter Test nach Fisher: $P=0,725, V=$ ,09).

Diese Tabelle ist aus urheberrechtlichen Gründen nicht in der Habilitationsschrift enthalten. Die Tabelle ist in der Autorenversion enthalten und kann über den Autor eingesehen werden.

Tabelle 4 - Invasivitätsgrad und molekulargenetische Analyse von HPV 16 und HPV 18

Anmerkung: Die hochgestellten Buchstaben sind zeilenweise zu lesen. Unterschiedliche hochgestellte Buchstaben verweisen auf einen signifikanten Unterschied $(P<.05$, Korrektur des Signifikanzniveaus nach Bonferroni).

Begriffserklärung IN=intraepitheliale Neoplasie, $\mathrm{N}=$ Anzahl

Gruppe 2: Es gab einen signifikanten Zusammenhang zwischen dem Vorkommen von HPV 16 (aber ohne HPV 18) und den Klassifizierungen IN1 bis IN3 $(x 2(2)=13,62, P=0,001)$. Dieser Effekt war von mittlerer Stärke $(V=, 35)$. In der Klasse IN3 war der Prozentsatz an Gruppe 2 signifikant höher als in den beiden anderen Klassen.

Gruppe 3: Es war kein Zusammenhang zwischen dem Vorkommen von HPV 18 (ohne HPV 16) und den Tumorstadien nachweisbar (exakter Test nach Fisher: $\mathrm{P}=0,725, \mathrm{~V}=, 09$ ). 
Durch diese Daten konnte gezeigt werden, dass durch rein zytologische Screenings, wie derzeit empfohlen, möglicherweise höhergradige (histologisch nachweisbare) Dysplasien übersehen werden. Eine HPV-spezifische Analyse könnte die Sensitivität erhöhen, da insbesondere HPV 16, aber auch HPV 18 (in IN3) stark mit dem IN-Grad korreliert (Tabelle 4; Abbildung 16-18).

\subsubsection{Publikation}

Unpublizierte Daten. Dissertation Bruno Hundsdörfer. (Doktorvater: Prof. Dr. med. Dr. h.c. mult. T. Ruzicka; mitbetreuender wissenschaftlicher Mitarbeiter: Dr. med. Markus Reinholz). 


\subsection{Epidemiologie von Condylomata acuminata}

Bei Genitalwarzen (Feigwarzen oder Condylomata acuminata (Abbildung 19) handelt es sich weltweit um die häufigste sexuell übertragbare virale Erkrankung. Die auslösenden Faktoren sind hier in mehr als $95 \%$ die HPVSubtypen 6 und 11 [46].

Genitalwarzen zeigen

sich

Diese Abbildung ist aus urheberrechtlichen Gründen nicht in der Habilitationsschrift enthalten. Die Abbildung ist in der Autorenversion enthalten und kann über den Autor eingesehen werden.

klinisch als braun-schwärzliche

bis hautfarbene, meist gruppiert

Bildmaterial der Klinik und Poliklinik der LMU München. Mit freundlicher Genehmigung Prof. T. Ruzicka.

stehende Papeln oder Plaques, die zu blumenkohlartig wachsenden Tumoren verschmelzen können (Buschke-Löwenstein-Tumoren). Männer wie auch Frauen können gleichermaßen von HPV-Infektionen betroffen sein. Bei Männern ist oft der Sulcus coronarius, der Penisschaft sowie das Präputium betroffen, bei Frauen hingegen vorrangig die Labia minora und majora sowie der Introitus vaginae [39].

Für den Patienten spielt beim Auftreten von HPV-Infektionen nicht nur das onkogene Potenzial, sondern zusätzlich auch die kosmetische Entstellung der Anogenitalregion eine Rolle [33]. Die kosmetische Belastung ist der häufigste Grund der betroffenen Patienten, einen Arzt aufzusuchen. Bei beiden Geschlechtern sind zusätzlich perianale und intraanale Manifestationen möglich. Weiterhin können in seltenen Fällen auch extraanogenitale Läsionen (beispielsweise axillär, labial oder enoral) auftreten [39]. Condylomata acuminata können über eine lange Zeit persistieren, Spontanremissionen sind laut Literatur möglich [6, 10].

Genitalwarzen werden vorrangig horizontal über Schmierinfektionen bei sexuellen Kontakten übertragen [39], können jedoch auch vertikal von Mutter zu Kind übertragen werden [21]. Die Lokalisation ist mit der mechanischen Belastung der betroffenen Region assoziiert. Weitere Risikofaktoren sind eine frühe Aufnahme der sexuellen Aktivität, hohe Promiskuität, Hochrisikosexualpraktiken und eine mangelnde Hygiene [39]. Die konsequente Anwendung von Kondomen und die HPV-Impfung vor Aufnahme sexueller Aktivitäten kann einer HPV-Infektion vorbeugen [39].

Nach Infektion der basalen Keratinozyten ist der HPV-Lebenszyklus stark an die Differenzierung der Epithelzellen gekoppelt (siehe Abbildung 1). Das Virus exprimiert in 
der Frühphase eine Vielzahl von Genen für die Proliferation, Apoptoseinhibition, Immunoevasion, virale Replikation und führt zur Fehlformation der ZytokeratinFilamentstrukturen. Die viralen Gene der Spätphase kodieren für das Viruskapsid und führen zur Virussynthese [26].

\subsubsection{Fragestellung: Welche Risikofaktoren bestehen? Ziel: Charakterisierung der} Patienten für gezielte Awareness-Maßnahmen.

Durch die starke Stigmatisierung der Erkrankung, bei gleichzeitig sehr hoher Prävalenz, bestehen nur wenig epidemiologische Daten. Es sollten daher mittels einer retrospektiven Analyse von betroffenen Patienten Risikogruppen in der Region München identifiziert werden, um anschließend die Awareness für die Erkrankung zu verbessern. Awareness ist die Krankheitswahrnehmung von den äußerst häufigen HPV-Infektionen in der Öffentlichkeit. Diese muss insbesondere bei Erkrankungen des Intimbereichs hoch sein, da hier durch Schamgefühl die Diagnose und Therapie unnötig verzögert werden, was zu einer Ausbreitung führt und gleichzeitig häufig invasivere Therapien zur Folge hat.

\subsubsection{Projektdurchführung}

Zur Untersuchung dieser Hypothese planten wir die retrospektive Untersuchung einer größeren Patientenkohorte (circa 1200 Patienten) der letzten drei Jahre im Rahmen der Immunambulanz der dermatologischen Klinik. Hier sollten epidemiologische Daten zum Auftreten von genitalen Warzen sowie Risikofaktoren identifiziert werden. Weiterhin planten wir die Analyse der Effektivität der verschiedenen Behandlungsformen. Die Daten sollten mit der gegenwärtigen Literatur verglichen werden. Eine Bescheinigung der ethisch-rechtlichen Unbedenklichkeit der retrospektiven Erhebung der Ethikkommission der LMU München lag vor (UE054-14 und UE 17-089).

Durch die geplante Studie sollten Patienten möglicherweise besser charakterisiert und gescreent werden. Weiterhin könnten die Therapieentscheidungen für den einzelnen Patienten besser abgestimmt und ultimativ die Verbreitung von HPV reduziert werden.

\subsubsection{Ergebnisse}

Es wurden Daten von 1124 Patienten mit Genitalwarzen zwischen Januar 2011 und März 2015 der Klinik und Poliklinik für Dermatologie und Allergologie retrospektiv ausgewertet. 
Von dem überwiegend männlichen Patientenkollektiv hatte mehr als die Hälfte der Patienten die deutsche Staatsbürgerschaft. Etwa die Hälfte der Patienten befand sich in einer festen Paarbeziehung (49,8\%), fast alle waren heterosexuell $(92,8 \%)$. Eine kleine Gruppe $(13,7 \%)$ der Patienten wurde zuvor gegen HPV immunisiert. Bei etwa zwei Drittel der Patienten (59,8\%) traten die Genitalwarzen zum ersten Mal auf. Der wahrscheinlichste Bereich der Infektion war der Penis bei männlichen Patienten und der Genitalbereich ohne weitere Spezifizierung bei weiblichen Patienten. Die Mehrheit der Patienten gab nur einen einzigen Infektionsort (62,8 \%) mit mehreren Papeln an. Die Therapie erwies sich oft als schwierig und langwierig, Rezidive waren häufig.

Aufgrund der Größe der Stichproben konnten wir anhand einer ausreichenden Datenbasis die gegenwärtige Epidemiologie von Genitalwarzen in der Tiefe analysieren und damit die Wirksamkeit der aktuellen Therapieoptionen veranschaulichen. Wir konnten außerdem zeigen, dass eine kombinatorische Therapie von Elektrokaustik und topischem Imiquimod eine große Wirksamkeit mit niedrigen Nebenwirkungen hatte.

Im Beobachtungszeitraum kam es zu einem Anstieg der Krankheitsfälle um 29,8 \% in der Klinik und Poliklinik für Dermatologie (Abbildung 20).

Diese Abbildung ist aus urheberrechtlichen Gründen nicht in der Habilitationsschrift enthalten. Die Abbildung ist in der Autorenversion enthalten und kann über den Autor eingesehen werden.

Abbildung 20 - Verteilung der HPV-Patienten über den Beobachtungszeitraum

In den Jahren 2011 bis 2014 zeigte sich ein Anstieg von 29,8\% an Patienten, welche mit Genitalwarzen in der Immunambulanz behandelt wurden. 


\section{Epidemiologie der Kohorte}

Die Verteilung der Geschlechter betrug bei den 1124 Patienten 943 Männer (83,9 \%) zu $181(16,1 \%)$ Frauen (Abbildung 21A). Bei den Patienten betrug der Mittelwert des Alters 36,5 Jahre, der Median 34,0 Jahre. Der jüngste Patient, der sich in dieser Zeit in der Immunambulanz vorstellte, war 1 Jahr und der älteste 83 Jahre alt (Abbildung 21B).

In die Gruppe der unter 18-Jährigen fielen 9 Personen, die Gruppe der 18- bis 25Jährigen zählte 102 Personen und in der Altersgruppe 26 bis 30 Jahre erfassten wir 239 Patienten. Die Anzahl in der Altersgruppe der 31- bis 40-Jährigen betrug 448 Patienten, in der Gruppe der 41- bis 50-Jährigen 209 und in der Gruppe der 51- bis 60-Jährigen 82 Patienten. 35 Personen waren über 60 Jahre (Abbildung 21B).

Insgesamt handelte es sich um 703 Patienten mit deutscher Staatsbürgerschaft, 67 Personen hatten die türkische Nationalität, 65 Patienten waren Südeuropäer, 69 Osteuropäer und 9 Patienten stammten aus Mitteleuropa. Weiterhin waren 14 Afrikaner, 37 Asiaten, 5 Amerikaner/Kanadier sowie 10 Personen, die zu keiner der oben genannten Gruppen zugeordnet wurden, im untersuchten Kollektiv. Keine Angabe machten 145 Personen (Abbildung 21C).

Von den 1124 Patienten machten 164 Personen eine Angabe zu Ihrem Beruf. 79 Personen waren Angestellte, 23 Arbeiter und 20 Personen Akademiker. Weitere 25 Patienten waren Schüler/Studenten, 6 Patienten waren Rentner, 9 waren arbeitslos und 2 waren Künstler (Abbildung 21D).

Von den 1124 Patienten machten 376 Patienten eine Angabe zu Ihrer sexuellen Orientierung. Die Gruppe der Heterosexuellen umfasste 349 Personen, dies entsprach 92,8 \% der Personen, die eine Angabe gemacht hatten. 24 Patienten waren homosexuell (Abbildung 21E).

Insgesamt machten 739 Personen eine Angabe zu Ihrem Beziehungsstatus zum Zeitpunkt der Behandlung. 371 Personen gaben an, Single zu sein, dies entsprach $50,2 \%$ der Personen, die eine Angabe gemacht hatten. 230 Patienten befanden sich in einer Partnerschaft, dies entsprach 31,1\%. 138 Personen und damit 18,7\% waren verheiratet (Abbildung 21F). 

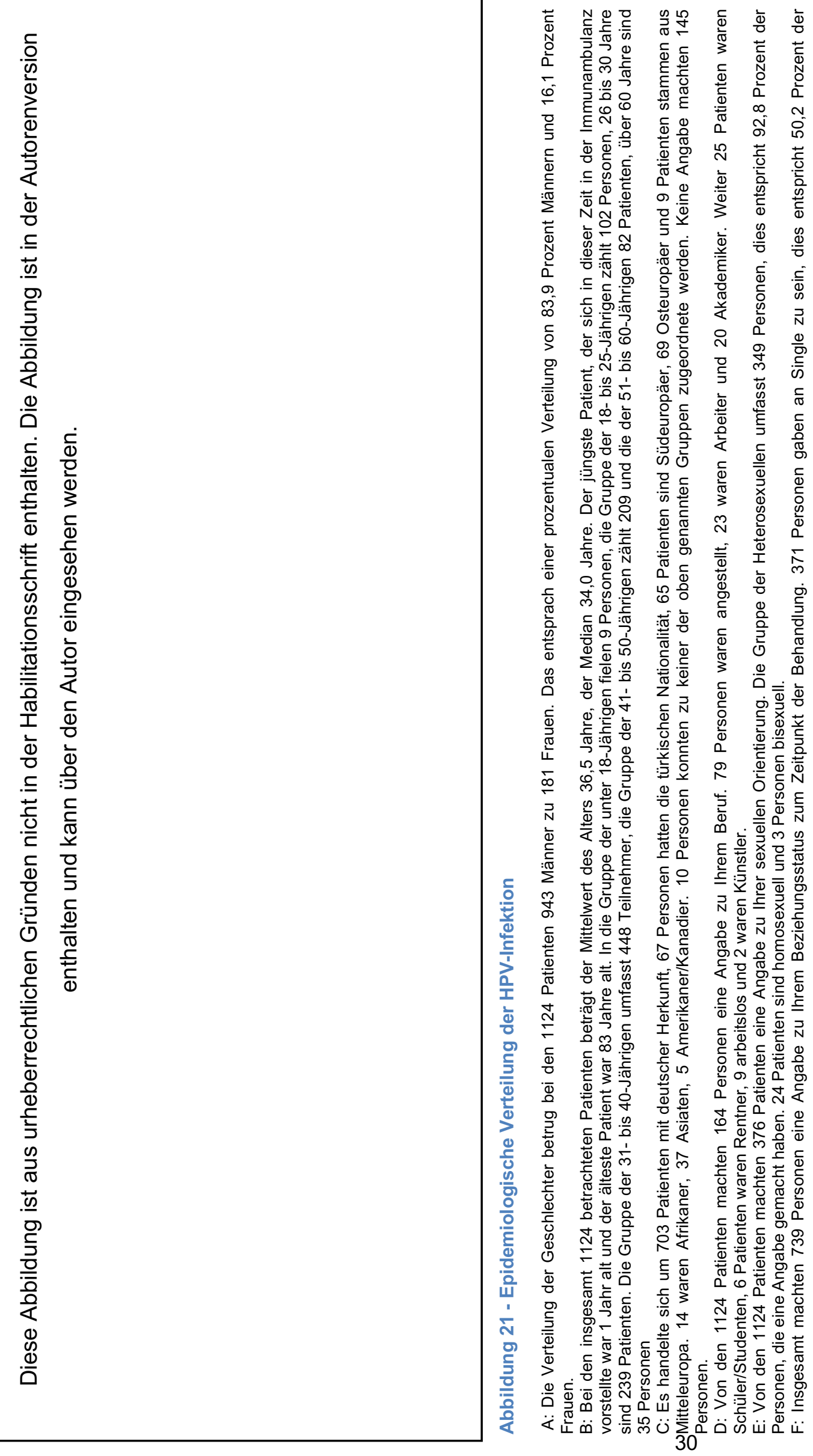
Dauer der symptomatischen Erkrankung

Es machten 937 Patienten eine Angabe bezüglich des Zeitraumes zwischen dem Auftreten der Feigwarzen und dem ersten Arztbesuch. 606 Personen gaben an, seit ein bis drei Monaten erkrankt zu sein, 123 Patienten litten seit vier bis sechs Monaten an den Feigwarzen. Bei 47 Personen betrug die Erkrankungsdauer sieben bis neun Monate und bei 65 Personen eine Dauer der Erkrankung von zehn bis zwölf Monaten vor. 50 Personen waren 13 bis 24 Monate und 33 Patienten 25 bis 60 Monate erkrankt, bis sie zum ersten Mal einen Arzt konsultierten. Länger als 61 Monate waren 13 Patienten erkrankt (Abbildung 22).

Diese Abbildung ist aus urheberrechtlichen Gründen nicht in der Habilitationsschrift enthalten. Die Abbildung ist in der Autorenversion enthalten und kann über den Autor eingesehen werden. 


\section{Lokalisation der Genitalwarzen}

Bei den Männern mit einer betroffenen Stelle zeigte sich eine alleinige Manifestation am Penis bei 238 Männern, sowie genital (nicht näher beschrieben) bei 118 Patienten. 39 Männer waren intraanal und 37 perianal betroffen. Nur das Scrotum war bei 19 Patienten und der Schamhügel bei 25 Personen betroffen. Einen alleinigen extraanogenitalen Befall gaben 10 Männer an, die Urethra isoliert war bei 9 Männern betroffen (Abbildung 23A).

Bei den Männern mit zwei betroffenen Stellen wurden am häufigsten der Penis + Schamhügel (78-mal) sowie Penis + Scrotum (69-mal) genannt. Weitere genannte Kombinationen waren genital + extragenital $(27-\mathrm{mal})$, Penis + anal $(27-\mathrm{mal})$, perianal + intraanal (21-mal), genital + anal (19-mal), Scrotum + anal (3-mal), Scrotum + Schamhügel (3-mal), extragenital + anal (2-mal), Schamhügel + anal (1-mal) und Penis + urethral (1-mal) (Abbildung 23A).

Bei den Männern mit drei betroffenen Stellen wurde am häufigsten die Kombination aus Penis + Scrotum + Schamhügel (38-mal) genannt. Weitere genannte Kombinationen waren Penis + Scrotum + anal (13-mal), Penis + anal + Schamhügel (6-mal), genital + extragenital + anal (3-mal) und Penis + Schamhügel + Urethra (1-mal) (Abbildung 23A). Von den weiblichen Patienten war von 158 von den insgesamt 181 Personen der Manifestationsort der Genitalwarzen dokumentiert. Eine alleinige Manifestation an den Schamlippen wurde bei 29 Frauen festgestellt, perianal bei 19 Frauen und intraanal bei 8 Personen, nur der Schamhügel war bei 3 Frauen betroffen. Eine alleinige genitale, nicht näher beschriebene Manifestation wurde bei 53 Personen nachgewiesen, extraanogenital zeigte sich nur bei 2 Frauen eine Erkrankung (Abbildung 23B).

Bei den betroffenen Patientinnen mit zwei betroffenen Stellen war am häufigsten die Kombination von Schamlippen + Schamhügel (15-mal) und genital + anal (11-mal). Weitere genannte Kombinationen waren Schamlippen + anal (7-mal), perianal + intraanal (2-mal), Schamhügel + anal (2-mal), extragenital + anal (1-mal) und Schamlippen + extragenital (1-mal) (Abbildung 23B).

Eine Manifestation an drei verschiedenen Stellen zeigte sich bei den Frauen an Schamhügel + Schamlippe + anal (Abbildung 23B). 


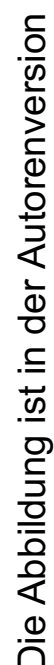

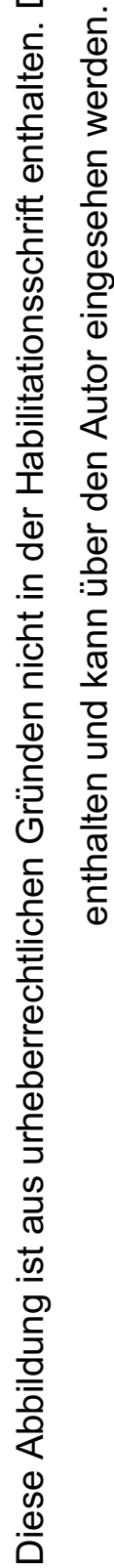

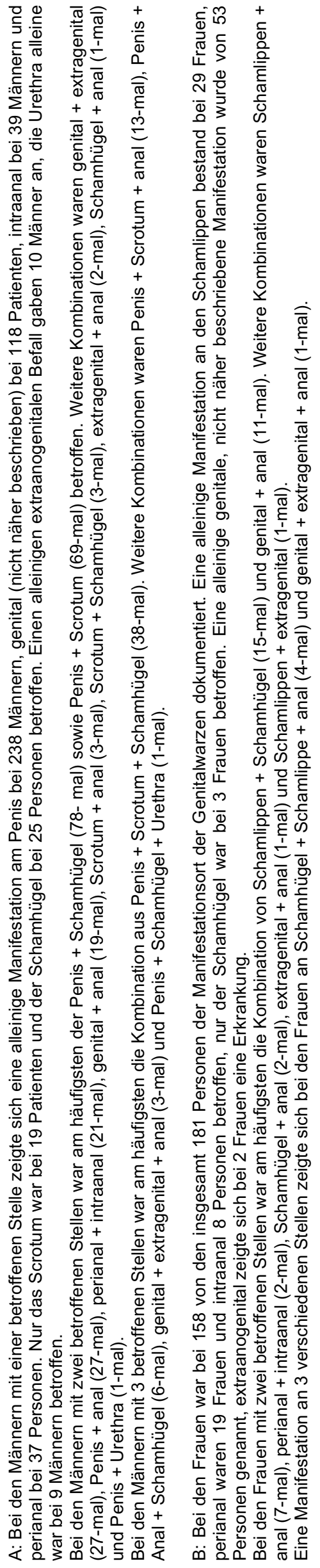




\section{Therapieversuche und Therapien}

Der erste Therapieversuch erfolgte bei 366 Personen topisch, bei 294 Patienten mittels erweiterter Therapie (Kryo-, Lasertherapie, Kauterisation), bei 274 Personen wurde eine Kombination aus beiden Therapieformen (topisch+erweitert) gewählt und 36 Personen erhielten keine Therapie. Bei 154 Patienten war die Therapieform unbekannt. Ein zweiter Therapieversuch erfolgte bei 556 Patienten, dies entsprach 49,5 Prozent der 1124 Patienten der Studie. 133 Patienten erhielten eine topische Therapie, 148 Personen eine erweiterte Therapie und 126 Patienten eine Kombination aus beiden Formen. Bei 149 Personen war unbekannt, welche Art der Therapie sie erhalten hatten. Ein dritter Therapieversuch erfolgte bei 247 Patienten. Davon erhielten 39 Personen eine topische Therapie, 28 eine erweiterte Therapie und 31 Patienten eine Kombination aus beiden Formen. (Abbildung 24A).

Die Grafik zeigt die Verteilung der verschiedenen erweiterten Therapieverfahren sowohl bei einer Monotherapie als auch in der Kombinationstherapie mit anderen erweiterten Therapieformen sowie in Kombination mit topischen Therapeutika. An erweiterten Therapeutika kam beim ersten Therapieversuch am häufigsten Elektrokauterisation (285-mal) zum Einsatz. Daneben wurden Kryotherapie (120-mal) und Lasertherapie (131-mal) verwendet. In 32 Fällen war die Art der erweiterten Therapie unbekannt. Beim zweiten Therapieversuch wurde in 80 Fällen Kryotherapie, bei 60 Patienten Lasertherapie und bei 134 Personen Elektrokauterisation angewandt. Im Rahmen des dritten Therapieversuchs kam bei 28 Personen die Kryotherapie zum Einsatz. Eine Lasertherapie erfolgte bei acht Personen und eine Elektrokauterisation bei 23 Patienten (Abbildung 24B).

Von 1124 Patienten erfolgte bei 1088 eine Therapie. Bei 219 Patienten war der erste Therapieversuch erfolgreich (= Komplettremission). Bei 299 Patienten war er dagegen nicht erfolgreich. Teilweise erfolgreich war die Therapie bei 73 Patienten und bei 497 Personen war der Therapieerfolg nicht bekannt. Von den 556 Personen, bei denen ein zweiter Therapieversuch erfolgte, war dieser bei 90 Personen erfolgreich, 21 Patienten verzeichneten einen Teilerfolg und bei 73 Personen war die Therapie nicht erfolgreich. Bei 372 Personen war der Erfolg unbekannt. Bei 247 Personen war ein dritter Therapieversuch notwendig, davon war die Therapie bei 39 Patienten erfolgreich, bei einer Person teilweise und bei 15 Personen nicht erfolgreich. Bei 192 Patienten war der Therapieerfolg unbekannt (Abbildung 24C). 


\section{Diese Abbildung ist aus urheberrechtlichen Gründen nicht in der Habilitationsschrift enthalten. Die Abbildung ist in der Autorenversion enthalten und kann über den Autor eingesehen werden.}

\section{Abbildung 24 - Anzahl der Therapieversuche und Differenzierung der Therapien}

A: Der erste Therapieversuch erfolgte bei 366 Personen topisch, bei 294 Patienten mittels erweiterter Therapie (Kryo-, Lasertherapie, Kauterisation), bei 274 Personen wurde eine Kombination aus beiden Therapieformen gewählt und 36 Personen erhielten keine Therapie. Bei 154 Patienten war die Therapieform unbekannt. Ein zweiter Therapieversuch erfolgte bei 556 Patienten, dies entsprach 49,5 Prozent der 1124 Patienten der Studie. 133 Patienten erhielten eine topische Therapie, 148 Personen eine erweiterte Therapie und 126 Patienten eine Kombination aus beiden Formen. Bei 149 Personen war unbekannt, welche Art der Therapie sie erhalten hatten. Ein dritter Therapieversuch erfolgte bei 247 Patienten. Es erhielten 39 Personen eine topische Therapie, 28 eine erweiterte Therapie und 31 Patienten eine Kombination aus beiden Formen.

B: Die Grafik zeigt die Verteilung der verschiedenen erweiterten Therapieverfahren sowohl bei einer Monotherapie als auch in der Kombinationstherapie mit anderen erweiterten Therapieformen sowie in Kombination mit topischen Therapeutika. An erweiterten Therapeutika kam beim ersten Therapieversuch am häufigsten Elektrokauterisation (285-mal) zum Einsatz. Daneben wurden Kryotherapie (120-mal) und Lasertherapie (131-mal) verwendet. In 32 Fällen war die Art der erweiterten Therapie unbekannt. Beim zweiten Therapieversuch wurde in 80 Fällen Kryotherapie, bei 60 Patienten Lasertherapie und bei 134 Personen Elektrokauterisation angewandt. Im Rahmen des dritten Therapieversuchs kam die Kryotherapie bei 28 Personen zum Einsatz. Lasertherapie erfolgte bei 8 Personen und Elektrokauterisation bei 23 Patienten.

C: Von 1124 Patienten erfolgte bei 1088 eine Therapie. Bei 219 Patienten war der erste Therapieversuch erfolgreich, bei 299 war er nicht erfolgreich. Teilweise erfolgreich war die Therapie bei 73 Patienten und bei 497 Personen war der Therapieerfolg nicht bekannt. Von den 556 Personen, bei denen ein zweiter Therapieversuch erfolgte, war dieser bei 90 Personen erfolgreich, 21 Patienten verzeichneten einen Teilerfolg und bei 73 Personen war die Therapie nicht erfolgreich. Bei 372 Personen war der Erfolg unbekannt. Bei 247 Personen war ein dritter Therapieversuch notwendig, davon war die Therapie bei 39 Patienten erfolgreich, bei einer Person teilweise und bei 15 Personen nicht erfolgreich. Bei 192 Patienten war der Therapieerfolg unbekannt. 


\section{Aufschlüsselung der topischen Therapien}

Am häufigsten wurde Imiquimod bei den behandelten Patienten angewandt, gefolgt von Podophyllotoxin und Grünteeextrakt. Die restlichen Patienten wurden mit Kombinationstherapien behandelt. Eine signifikante Überlegenheit einer Therapieform über eine andere konnte auf Grund der Ungleichverteilung der verschiedenen Therapiegruppen nicht berechnet werden (Abbildung 25).

Anzahl der Läsionen und Partnerbeteiligung

Diese Abbildung ist aus urheberrechtlichen Gründen nicht in der Habilitationsschrift enthalten. Die Abbildung ist in der Autorenversion enthalten und kann über den Autor eingesehen werden.

Einzelne Papeln wurden bei 367 Patienten beobachtet, multiple Papeln wurden bei 580 Patienten beobachtet (Abbildung 26 A,B). 199 Patienten berichteten, dass der Partner nicht betroffen sei. Bei 87 Patienten war der Partner betroffen. 838 Patienten machten hierzu keinen Angaben (Abbildung $26 \mathrm{C}$ ).

Diese Abbildung ist aus urheberrechtlichen Gründen nicht in der Habilitationsschrift enthalten. Die Abbildung ist in der Autorenversion enthalten und kann über den Autor eingesehen werden.

Abbildung 26 - Weitere epidemiologische Daten

\subsubsection{Publikation}

Unpublizierte Daten. Dissertation Nicole Oeggle. (Doktorvater: Prof. Dr. med. Dr. h.c. mult. T. Ruzicka; mitbetreuender wissenschaftlicher Mitarbeiter: Dr. med. Markus Reinholz). 


\subsection{HPV-bedingte Analkarzinome bei HIV}

Die Infektion mit HIV ist hochgradig mit der Prävalenz von HPV-Infektionen, einer erhöhten Inzidenz von analen intraepithelialen Neoplasien (AIN) sowie einem erhöhten Risiko für Analkrebs assoziiert [18, 33].

Bei HIV-positiven men who have sex with men (MSM; veraltet: "homosexuellen Männern") mit AIN oder Analkarzinomen können in über $90 \%$ hrHPV nachgewiesen werden [18].

Die meisten immunkompetenten Individuen autoeradizieren das Virus nach einer initialen Infektion. Immunsupprimierte Patienten haben ein höheres Risiko für persistierende Infektionen als auch für maligne Entartung. AIN stellen eine Präkanzerose des Analkarzinoms dar und werden als niedriggradig (AIN 1) und hochgradig (AIN 2 und 3) klassifiziert (Abbildung 27). AIN 1 wird nicht als direkte Vorstufe des Analkarzinoms bezeichnet, wohingegen AIN 2 und AIN 3 prämaligne zu sein scheinen und sich zu einem Analkarzinom entwickeln können [33].

Diese Abbildung ist aus urheberrechtlichen Gründen nicht in der Habilitationsschrift enthalten. Sie lässt sich jedoch über untenstehende Publikation direkt über den Verlag aufrufen.

Abbildung 27 - Anale intraepitheliale Neoplasien

AIN 1 leichtgradige, AIN 2 mittelgradige, AIN 3 hochgradige Dysplasie aus Dietrich et al. [21]

Bei MSM bestehen eine höhere Prävalenz von analen HPV Infektionen (>90 \%) und AIN (>70 \%) sowie ein 80- bis 100-fach erhöhtes Risiko für Analkrebs. Eine HIV-Infektion bei MSM verdoppelt das Risiko, zusätzlich ein Analkarzinom zu entwickeln. Von besonderer Bedeutung ist hier die Progression von hochgradigen AIN zu Analkarzinomen. Diese läuft bei HIV-positiven Patienten schneller ab. Analkarzinome zeigen viele Gemeinsamkeiten mit Zervixkarzinomen, sowohl einschließlich ihrer histopathologischen Eigenschaften als auch bezüglich ihrer HPV-Infektionsmuster mit verschiedenen HPVTypen. Analog zum Zervixkarzinom kann ein regelmäßiges Screening möglicherweise Analkarzinome verhindern. Ein Screening von HIV-positiven Patienten für AIN und Analkarzinomen erhöht die Qualitäts-adjustierte Lebenserwartung und ist kosteneffizient. Die antiretrovirale Therapie (ART) scheint hingegen nur einen geringen Einfluss auf die Prävalenz oder den Progress von AIN zu Analkarzinomen zu haben [33]. 
2.4.1. Fragstellung: Wie sensitiv ist das durch die Leitlinie vorgeschlagene Analkrebsscreening mittels Bürstenabstrich? Ist eine hochauflösende Anoskopie überlegen?

Kürzlich hat die Deutsche AIDS Gesellschaft e.V. eine Leitlinie zur Prävention, Diagnose und Therapie von AIN und Analkarzinomen bei HIV-positiven Patienten veröffentlicht. Es fehlen jedoch größere Studien bezüglich des Einflusses der vorgeschlagenen Prozeduren auf die Prävention des Analkarzinom [18]. In einer retrospektiven Datenanalyse sollte untersucht werden, ob die empfohlenen Bürstenabstriche mit anschließender Zytologie und PCR für diese Risikogruppe ausreichend sind oder ob eine hochauflösende Anoskopie (HRA, hrAnoskopie) überlegen ist.

\subsubsection{Projektdurchführung}

Um die empfohlenen Screening-Prozeduren zu validieren, sollten die Daten von circa 120 männlichen und weiblichen Patienten mit HIV-Infektion der Immunambulanz der dermatologischen Klinik untersucht werden. Hierzu sollten Analzytologie, HPVTypisierung der Zytologie und die Ergebnisse der HRA retrospektiv ausgewertet werden.

Die Ergebnisse der Analzytologie sollten dann mit den Ergebnissen der HPVTypisierung aus der Zytologie und denen der hrAnoskopie korreliert werden. Die Ergebnisse könnten möglicherweise zu einem verbesserten Screening und damit zu einer frühzeitigeren Behandlung führen.

\subsubsection{Ergebnisse}

Unsere Ergebnisse zeigten, dass das Screening durch Analzytologie nur eine Minderheit der Patienten mit hochgradiger AIN (AIN 3) Histologie identifizierte. Patienten mit normaler Zytologie (NILM, „zytologisch eingestuft negativ für intraepitheliale Läsion oder Malignität“, $n=5,29,4 \%$ ), „atypischen Plattenepithelzellen mit unklarer Malignität“ (ASCUS; atypical squamous cells of undetermined significance; $n=5,71,4 \%$ ) und niedergradigen Plattenepithel-Läsionen (LSIL; $=8,44,5 \%$ ) zeigten bei der histologischen Aufarbeitung häufiger dysplastische Läsionen (AIN 2 und 3) als erwartet. Darüber hinaus wurde eine hochgradige Plattenepithel-Intraepithel-Läsion (HSIL) stark mit dem Nachweis von onkogenen hrHPV assoziiert. 
Schlussfolgerung

Analzytologie als alleiniges Screening-Tool für Anal-Krebs war nicht in der Lage, AnalDysplasien bei einer beträchtlichen Anzahl von Patienten zu erkennen. Darüber hinaus könnten HPV-Typisierung und eventuell weitere Biomarker verwendet werden, um diejenigen Patienten mit einem höheren Risiko der Entwicklung von Analkarzinomen zu identifizieren, um sie genauer zu überwachen oder direkt einer HRA zu zuführen.

Charakterisierung der Kohorte

CD4-Zellzahl

Die niedrigste $\mathrm{CD}^{+}$-Zellzahl, die in der Vergangenheit bei der Studienpopulation festgestellt wurde, betrug $<200$ Zellen / $\mu \mathrm{L}$ bei 39 (31,7\%) Patienten, 200 bis 500 Zellen $/ \mu \mathrm{l}$ in $35(28,5 \%)$ und $\geq 500$ Zellen $/ \mu \mathrm{L}$ bei elf (8,9 \%) Patienten. Bei der Betrachtung der aktuellen $\mathrm{CD}^{+}$-Zellzahlen zeigten sich, dass sieben (5,7\%) Patienten 200 Zellen $/ \mu \mathrm{L}$ hatten, 30 (24,4 \%) 200-500 Zellen / $\mu \mathrm{L}$ und 48 (39,0 \%) $\geq 500$ Zellen $/ \mu \mathrm{L}$. Bei $38(30,9 \%)$ Patienten waren die CD4 ${ }^{+}$-Zellzahl und Nadir unbekannt (Tabelle 5). Die Korrelationsanalyse zeigte keinen Zusammenhang zwischen der Zytologie und der letzten $\mathrm{CD} 4^{+}$-Zellzahl oder Zytologie sowie $\mathrm{CD} 4^{+}$und dem Nadir (Daten nicht gezeigt).

Zytologie

Von allen untersuchten Analzytologien ( $n=123)$ waren 69 unauffällig, 26 zeigten LSIL, 21 HSIL und 7 ASCUS (Tabelle 5). Weder Geschlecht, CD4 ${ }^{+}$T-Zell-Nadir, die jüngste $\mathrm{CD}^{+}$absolute T-Zellzahl noch die Sexualpraktik zeigten einen signifikanten Einfluss auf die zytologische Abstufung (Daten nicht gezeigt).

HPV-Typisierung

Onkogene HPV-Subtypen wurden in 55,3\% $(n=68)$ nachgewiesen. Patienten, die mit normaler Zytologie diagnostiziert wurden, zeigten onkogene HPV-Subtypen in 33,3 \% (n = 23), Patienten mit LSIL in 88,5\% ( $n=23)$, Patienten mit HSIL in 90,5\% ( $n=19)$ und Patienten mit ASCUS in $42,9 \%$ der Fälle. Die häufigsten Subtypen waren HPV 31/33/35/39/45/51/52/56/58/59/66/68 (Tabelle 5). Die Infektion mit den spezifischen HPV-Subtypen war stark mit dem Grading (LSIL bzw. HSIL) assoziiert. 
Diese Tabelle ist aus urheberrechtlichen Gründen nicht in der Habilitationsschrift enthalten. Sie lässt sich jedoch über untenstehende Publikation direkt über den Verlag aufrufen.

Tabelle 5 - Demographie, klinische Charakteristik, HPV-Genotypisierung und Zytologie

\section{CD4 ${ }^{+}$-Zellzahl}

Die niedrigste $\mathrm{CD} 4^{+}$-Zellzahl, die in der Vergangenheit bei der Studienpopulation festgestellt wurde, betrug $<200$ Zellen $/ \mu \mathrm{L}$ bei $39(31,7 \%)$ Patienten, 200 bis 500 Zellen $/ \mu \mathrm{l}$ in $35(28,5 \%)$ und $\geq 500$ Zellen $/ \mu \mathrm{L}$ in elf $(8,9 \%)$ Patienten. Bei der Betrachtung der aktuellen CD4 ${ }^{+}$-Zellzahlen zeigten sich, dass sieben $(5,7 \%)$ Patienten 200 Zellen $/ \mu \mathrm{L}$ hatten, 30 $(24,4 \%)$ 200-500 Zellen $/ \mu \mathrm{L}$ und $48(39,0 \%) \geq 500$ Zellen $/ \mu \mathrm{L}$. Bei $38(30,9 \%)$ Patienten waren die CD4 ${ }^{+}$-Zellzahl und Nadir unbekannt (Tabelle 5). Die Korrelationsanalyse zeigte keinen Zusammenhang zwischen der Zytologie und der letzten $\mathrm{CD} 4^{+}$Zellzahl oder Zytologie sowie $\mathrm{CD4} 4^{+}$und dem Nadir (Daten nicht gezeigt).

\section{Zytologie}

Von allen untersuchten Analzytologien $(n=123$ ) waren 69 unauffällig, 26 zeigten LSIL, 21 HSIL und 7 ASCUS (Tabelle 5). Weder Geschlecht, CD4 $4^{+}$T-Zell-Nadir, die jüngste $C D 4^{+}+$absolute T-Zellzahl noch die Sexualpraktik zeigten einen signifikanten Einfluss auf die zytologische Abstufung (Daten nicht gezeigt).

\section{HPV-Typisierung}

Onkogene HPV-Subtypen wurden in 55,3\% $(n=68)$ nachgewiesen. Patienten, die mit normaler Zytologie diagnostiziert wurden, zeigten onkogene HPV-Subtypen in 33,3\% ( $n=23)$, Patienten mit LSIL in 88,5\% ( $n=23)$, Patienten mit HSIL in $90,5 \%(n=19)$ und Patienten mit ASCUS in $42,9 \%$ der Fälle. Die häufigsten Subtypen waren HPV 31/33/35/39/45/51/52/56/58/59/66/68 (Tabelle 1). Die Infektion mit den spezifischen HPV-Subtypen war stark mit dem Grading (LSIL bzw. HSIL) assoziiert.

Aus Dietrich et al. [13]

Es wurden Doppelt- oder Dreifachinfektionen mit verschiedenen HPV-Typen häufiger bei HSIL (12 von 21 Patienten) als LSIL (9 von 26 Patienten) oder normaler Zytologie (vier von 69) gefunden. Keine HPV-Infektion wurde in 44,7\% $(n=55)$ aller Patienten gefunden. Bei 66,7\% aller Patienten mit normaler Zytologie, 11,5\% mit LSIL und 9,5\% mit HSIL wurde keine HPV-DNA nachgewiesen. Die Rate der HPV-Infektion sowie die Anzahl der beobachteten HPV-Co-Infektionen stieg mit dem Grad der zytologischen Dysplasie (Tabelle 5, Abbildung 28 und 29). 
Diese Abbildung ist aus urheberrechtlichen Gründen nicht in der Habilitationsschrift enthalten.

Sie lässt sich jedoch über untenstehende Publikation direkt über den Verlag aufrufen.

Abbildung 28 - Anzahl der jeweiligen Läsion

Es wurden Doppelt- oder Dreifachinfektionen mit verschiedenen HPV-Typen häufiger bei HSIL (12 von 21 Patienten) als LSIL (9 von 26 Patienten) oder normaler Zytologie (vier von 69) gefunden. Keine HPV-Infektion wurde in $44,7 \%(n=55)$ aller Patienten gefunden. Bei $66,7 \%$ aller Patienten mit normaler Zytologie, $11,5 \%$ mit LSIL und 9,5\% mit HSIL wurde keine HPV-DNA nachgewiesen.

Aus Dietrich et al. [13]
Diese Abbildung ist aus urheberrechtlichen Gründen nicht in der Habilitationsschrift enthalten. Sie lässt sich jedoch über untenstehende Publikation direkt über den Verlag aufrufen.

\begin{abstract}
Abbildung 29 - Prozentualer Anteil von HPV-Subtypen in den Analzytologien

Die Rate der HPV-Infektion sowie die Anzahl der beobachteten HPV-CoInfektionen stieg mit dem Grad der zytologischen Dysplasie.
\end{abstract}

Aus Dietrich et al. [13]

\section{Histologie}

Knipsbiopsien wurden im Falle eines abnormen Schleimhautfärbemusters während der HRA ( $n=57$ ) entnommen. Bei insgesamt 15 Patienten mit HSIL, 18 mit LSIL, 17 mit normaler Zytologie und 7 mit ASCUS wurden Biopsien entnommen. Die histologische Untersuchung ergab 11 niedriggradige AIN, 28 hochgradige AIN, 8 Condylomata acuminata und 10 negative Ergebnisse (Abbildung 30).

Es erfolgten weitere Subgruppenanalysen der Histologien in Bezug auf Geschlecht, sexuelle Orientierung und sexuelle Praxis. Die meisten Patienten praktizierten analen Geschlechtsverkehr, während 18 Patienten dies nicht angaben. Insgesamt wurden aus dieser Gruppe nur sechs Biopsien gewonnen (Tabelle 5). 
Diese Abbildung ist aus urheberrechtlichen Günden nicht in der Habilitationsschrift enthalten.

Sie lässt sich jedoch über untenstehende Publikation direkt über den Verlag aufrufen.

Abbildung 30 - Flußdiagramm bzgl. der Patientendiagnostik

Knipsbiopsien wurden im Falle eines abnormen Schleimhautfärbemusters während der HRA $(n=57)$ entnommen. Bei insgesamt 15 Patienten mit HSIL, 18 mit LSIL, 17 mit normaler Zytologie und 7 mit ASCUS wurden Biopsien entnommen. Die histologische Untersuchung ergab 11 niedriggradige AIN, 28 hochgradige AIN, 8 Condylomata acuminata und 10 negative Ergebnisse (Abbildung 31).

Aus Dietrich et al. [13]

Konkordanz zwischen Zytologie und Histologie

Der Nachweis von AIN 2 und 3 beim Zytologiebefund HSIL war hoch mit 10 von 15 $(66,7 \%)$ Patienten. In der HSIL-Gruppe wurden kein negativer Befund und nur zwei AIN 1 Histologien festgestellt.

Interessanterweise zeigten in dieser Gruppe drei von 15 Proben (20\%) Condylomata acuminata. Diese mussten daher als möglicher Confounder betrachtet werden.

Für LSIL war die Konkordanz mit nur fünf von 18 (27,8\%) übereinstimmenden Ergebnissen niedriger. LSIL wurde in Bezug auf AIN 1 analysiert. Allerdings wurden bis zu acht von 18 Histologien in der LSIL-Gruppe AIN 2 oder AIN 3 eingestuft. Die Anzahl der hochdysplastischen intraepithelialen Neoplasien war daher für LSIL in unserer Kohorte stark unterbewertet. Drei von 18 (16,7\%) Patienten zeigten Condylomata acuminata (Tabelle 2).

Nur sieben von $17(41,2 \%)$ Patienten mit normaler Zytologie zeigten mit den histologischen Befunden übereinstimmende Ergebnisse. Überraschenderweise hatten die Patienten trotz normaler Zytologie AIN 1 (23,5\%), AIN 2 (5,9\%) und bis zu vier Patienten AIN 3 (23,5\%).

Schließlich konnten sieben ASCUS mit den entsprechenden Histologien korreliert werden. Davon war ein Befund negativ (14,3\%) und ein Befund zeigte Condylomata acuminata (14,3\%). Allerdings zeigten fünf ASCUS-Zytologien AIN 3-Histopathologien $(71,4 \%)$. 
Zusammenfassend war die Anzahl der hochgradigen Dysplasien durch die zytologischen

Befunde deutlich unterschätzt worden. Dies war insbesondere in der Gruppe der

Unauffälligen und der ASCUS-Gruppe der Fall (Tabelle 6, Abbildung 31).

Diese Abbildung ist aus urheberrechtlichen Günden nicht in der Habilitationsschrift enthalten.

Sie lässt sich jedoch über untenstehende Publikation direkt über den Verlag aufrufen.

Abbildung 31 - Histologie im Vergleich zum zytologischen Befund (absolut)

Der Nachweis von AIN 2 und 3 beim Zytologiebefund HSIL war hoch mit 10 von 15 (66,7\%) Patienten. In der HSIL-Gruppe wurden kein negativer Befund und nur zwei AIN 1 Histologien festgestellt. Für LSIL war die Konkordanz mit nur fünf von 18 $(27,8 \%)$ übereinstimmenden Ergebnissen niedriger. LSIL wurde in Bezug auf AIN 1 analysiert. Allerdings wurden bis zu acht von 18 Histologien in der LSIL-Gruppe AIN 2 oder AIN 3 eingestuft. Drei von 18 (16,7\%) Patienten zeigten Condylomata acuminata. Sieben von $17(41,2 \%)$ Patienten mit normaler Zytologie zeigten mit den histologischen Befunden übereinstimmende Ergebnisse. Es gab Patienten, die trotz normaler Zytologie eine AIN 1 (23,5\%), eine AIN 2 (5,9\%) und bis zu vier Patienten eine AIN $3(23,5 \%)$ in der histologischen Untersuchung aufwiesen. Es konnten sieben ASCUS Zytologien mit den entsprechenden Histologien korreliert werden. Davon war ein Befund negativ $(14,3 \%)$ und ein Befund zeigte Condylomata acuminata (14,3\%). Allerdings zeigten fünf ASCUS-Zytologien AIN 3-Histopathologien(71,4\%) (zusammengefasste Darstellung Tabelle 6).

Aus Dietrich et al. [13] 


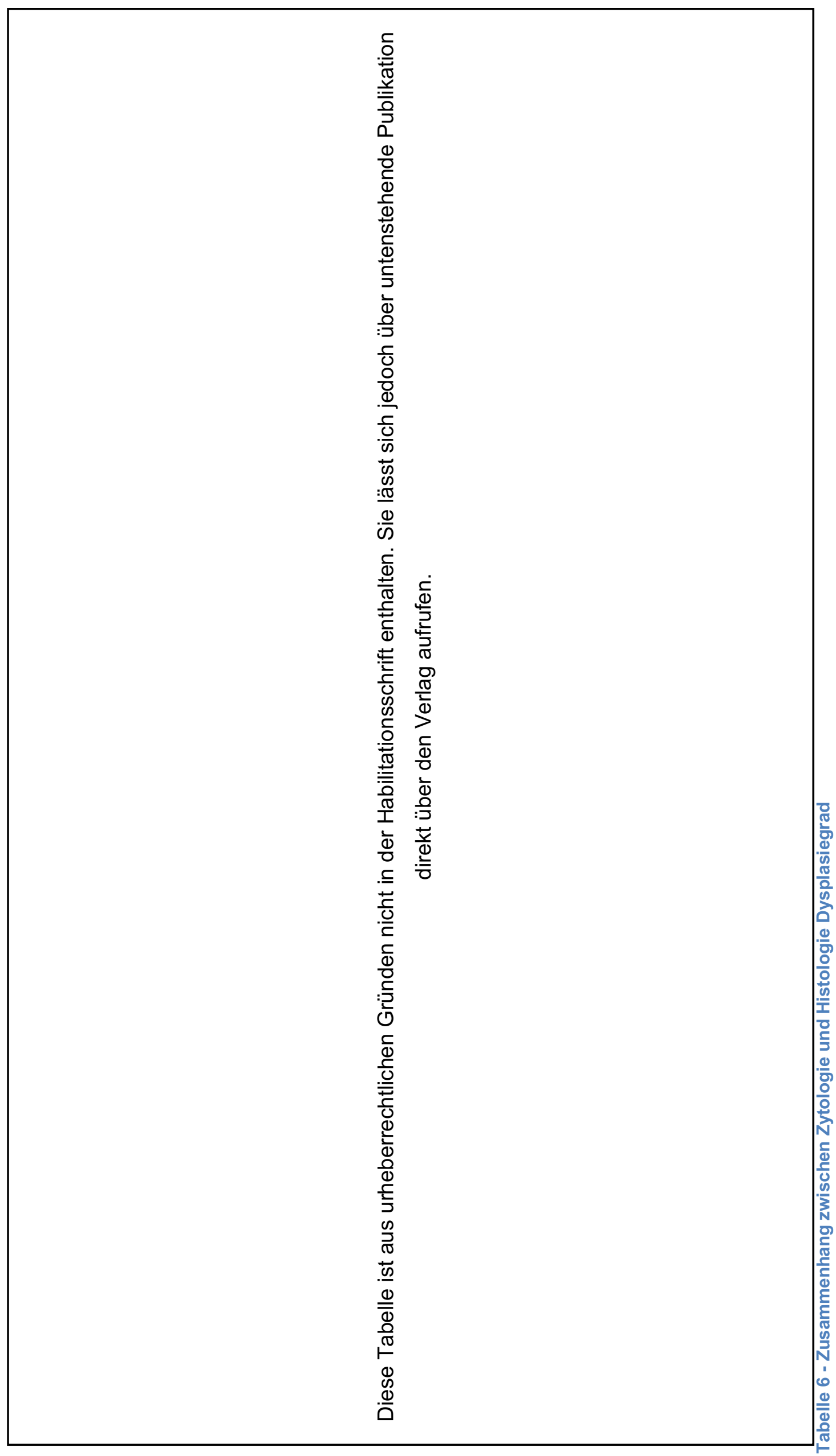

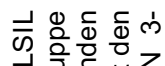

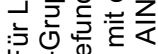

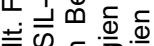
ब 这 क 등응

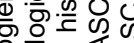

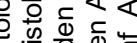

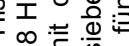
$z \subset \subset \bar{\Phi}$ >

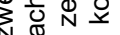
N 을 응 응 品. 을 훙ㅇㅇㅇ ه 政

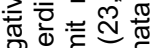
$\Phi$

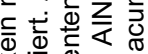

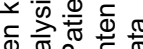

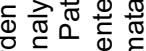
중 乙 造过安

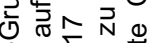

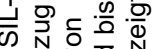
工 $>$

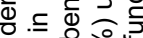
ᄃ $\frac{0}{0} \omega$

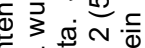

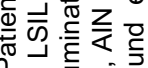
홍ㅎㅇㅇㅇㅇ (1)

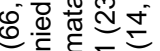
워을츨 䉼 응

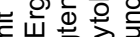
次 등다. Tा है

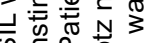
क्ञ

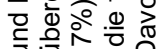
它

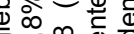
응 匀 సᄎ은 등 $\bar{\alpha}$ ब。 品出

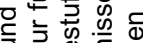
$\checkmark$ 잉응

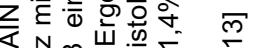
Nom 西 $\mathrm{z}$ > 论

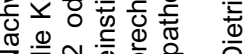

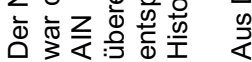




\subsubsection{Publikation}

Dietrich A, Hermans C, Heppt MV, Ruzicka T, Schauber J, Reinholz M

Human papillomavirus status, anal cytology and histopathological outcome in HIV-positive patients

J Eur Acad Dermatol Venereol. 2015 Oct;29(10):2011-8. doi: 10.1111/jdv.13205. Epub 2015 Aug 14. IF( 2013): 3.105 


\subsection{Die Rolle von HPV bei spinozellulären Karzinomen und aktinischen Keratosen}

Die hrHPV sind bekannte Auslöser des Zervixkarzinoms [40,61]. Darüber hinaus ist der Zusammenhang dieser Viren mit oropharyngealen Karzinomen und anderen Genitalkarzinomen wie Anogenital-, Penis- und Vulvakarzinomen ebenfalls gut beschrieben $[8,53,58]$. HPVs sind doppelsträngige DNA (dsDNA) Viren, die selektiv Keratinozyten der Schleimhaut und des Hautepithels infizieren. Bisher wurden mehr als 180 HPV-Subtypen identifiziert und als hoch- oder risikoarm nach ihrem onkogenen Potenzial klassifiziert [12]. Eine persistente Infektion der Basalzellen mit Hochrisiko-HPV kann die Expression der HPVOncoproteine E6 und E7 hervorrufen, die die Tumorsuppressorgene p53 bzw. Rb hemmen, was zu einem Verlust der Zellzykluskontrolle und zur Förderung des Krebswachstums führt [16, 36, 47]. E6- und E7-Oncoproteine stören auch direkt Komponenten der InterferonSignalwege und reduzieren die Typ-1-Interferon-Antwort, die für die Kontrolle der Virusinfektion kritisch ist [51].

Basierend auf dieser Theorie haben über 100 Studien die Beziehung zwischen HPV und kutanem Plattenepithelkarzinom (cuSCC) unter Verwendung verschiedener Probenentnahmen und Nachweisverfahren untersucht [54]. Eine Metaanalyse der Literatur zur Bestimmung der Assoziation zwischen HPV und cuSCC zeigte, dass es eine höhere Prävalenz von HPV in cuSCC von immunsupprimierten Patienten im Vergleich zu immunkompetenten Patienten gibt [54].

Verschiedene HPV-Typen haben unterschiedliche Gewebetropismen und kutane $\beta$ Gattungs-HPVs ( $\beta$-HPVs) sind stark mit cuSCC in einer spezifischen Gruppe von Patienten mit Epidermodysplasia verruciformis (EV) assoziiert, einer erblichen Störung, die durch eine anormale Anfälligkeit für $\beta$-HPVs $[2,31]$ gekennzeichnet ist. Dementsprechend konzentrierten sich viele neuere Studien auf die ätiologische Rolle von $\beta$-HPV in cuSCC und aktinischer Keratose (AK) $[4,5,9,31,41,55]$. Obwohl $\beta$-HPVs DNA in 30\% der cuSCCPatienten nachweisbar war, wurde diese auch in einem vergleichbaren Anteil bei normalen Hautproben gefunden [3]. Darüber hinaus zeigte eine Studie mit messenger RNA (mRNA)Transkriptom-Sequenzierung zur Beurteilung der $\beta$-HPV-Genexpression in cuSCC, dass die $\beta$-HPV-mRNA-Menge extrem niedrig war, was darauf hindeutet, dass $\beta$-HPV in cuSCC nicht aktiv ist.

Die Assoziation von Hochrisiko-a-HPV mit cuSCC oder Bowen-Krankheit wurde in einigen Publikationen [30, 42, 44, 60] berichtet. Allerdings bleibt die Korrelation zwischen Hochrisikoa-HPV und cuSCC weiterhin unklar, da frühere Berichte widersprüchliche Ergebnisse gezeigt 
haben. Im Allgemeinen sind Hochrisiko-a-HPV-Infektionen häufiger bei sexuell aktiven jungen Erwachsenen. Diese Studie hatte zum Ziel, die Rolle von $\alpha-H P V$ in cuSCC und aktinischen Keratosen zu untersuchen.

\subsubsection{Fragestellung: Welche Rolle spielt HPV bei cuSCC und AKs?}

\subsubsection{Projektdurchführung}

Hoch-Risiko- $\alpha-G a t t u n g$ menschlicher Papillomaviren ( $\alpha$-HPVs) sind mit zervikalen und anderen Genitalkarzinomen assoziiert, aber ihre Korrelation mit kutanem Plattenepithelkarzinom (cuSCC) oder präkanzerösen Hautläsionen bleibt umstritten.

Wir untersuchten die HPV-DNA-Prävalenz im Hautgewebe von 40 jüngeren (unter 60) und 40 älteren (über 60) cuSCC-Patienten, 48 Patienten mit aktinischer Keratose (AK) und 10 Kontrollen aus gesunder Haut jüngerer Patienten (Tabelle 7).

Diese Tabelle ist aus urheberrechtlichen Gründen nicht in der Habilitationsschrift enthalten.

Die Tabelle ist in der Autorenversion enthalten und kann über den Autor eingesehen werden.

Tabelle 7 - Klinische Charakteristika der Patienten mit AKs und cuSCC

Wir untersuchten die HPV-DNA-Prävalenz im Hautgewebe von 40 jüngeren (unter 60) und 40 älteren (über 60) cuSCCPatienten, 48 Patienten mit aktinischer Keratose (AK) und 10 Kontrollen aus gesunder Haut jüngerer Patienten. Diese Subgruppen wurden nach Risikofaktoren für spinozelluläre Karzinome stratifiziert. 


\subsubsection{Ergebnisse}

Die Durchseuchung von hrHPV-DNA war bei jungen cuSCC-Patienten (65\%) signifikant höher als bei älteren cuSCC-Patienten (50\%). Im Gegensatz dazu wurden bei 48 AKPatienten keine hrHPVs nachgewiesen (Abbildung 32). Der häufigste HPV-Typ bei HPVinfizierten cuSCC-Patienten war der Subtyp 16 (Abbildung 32). Ein Vergleich zwischen Keratoakanthomen und anderen cuSCC wurde nicht durchgeführt.

Diese Abbildung ist aus urheberrechtlichen Gründen nicht in der Habilitationsschrift enthalten. Die Abbildung ist in der Autorenversion enthalten und kann über den Autor eingesehen werden. 
Die Sonnenexposition bzw. das Auftreten in sonnenexponierten Arealen in den jeweiligen Subgruppen in Bezug auf die HPV-Durchseuchung schien keinen Einfluss auf die Entstehung von SCC zu haben (Abbildung 33). Interessanterweise zeigte sich sogar eine höhere Durchseuchung mit HPV in nicht-sonnenexponierten, typischerweise mit Kleidung bedeckten Arealen (Stamm, Oberarme, sowie Oberschenkel).

Diese Abbildung ist aus urheberrechtlichen Gründen nicht in der Habilitationsschrift enthalten. Die Abbildung ist in der Autorenversion enthalten und kann über den Autor eingesehen werden.

Abbildung 33 - Korrelation zwischen UV-Exposition und HPV-Infektion in AKs und cuSCC

Die Sonnenexposition bzw. das Auftreten in sonnenexponierten Arealen in den jeweiligen Subgruppen in Bezug auf die HPV-Duchseuchung schien keinen Einfluss auf die Entstehung von SCC zu haben. Interessanterweise zeigte sich sogar eine höhere Durchseuchung mit HPV in nicht-sonnenexponierten, typischerweise mit Kleidung bedeckten Arealen (Stamm, Oberarme, sowie Oberschenkel). 
Die Durchseuchungrate von hrHPV bei immunsupprimierten, jungen cuSCC-Patienten in SCC lag bei $100 \%$. Dahingegen wiesen nur $70 \%$ der Tumore von immunkompetenten, jungen Patienten hrHPV auf (Abbildung 34). Unsere Ergebnisse deuteten darauf hin, dass Hochrisiko- $\alpha-H P V$, vor allem die HPV-16-Infektion, ein Risikofaktor für cuSCC bei jungen, vor allem immunsupprimierten Patienten sein könnte, aber nicht für die Entstehung von AK. Daher könnte die HPV-Impfung in dieser Population vorbeugend sein, um SCC zu entwickeln.

Diese Abbildung ist aus urheberrechtlichen Gründen nicht in der Habilitationsschrift enthalten. Die Abbildung ist in der Autorenversion enthalten und kann über den Autor eingesehen werden.

Abbildung 34 - Immunstatus und HPV bei Patienten mit Spinalzellkarzinomen

Die Durchseuchungrate bei immunsupprimierten, jungen cuSCC-Patienten von hrHPV in SCC lag bei $100 \%$. Dahingegen wiesen nur 70\% der Tumore von immunkompetenten, jungen Patienten hrHPV auf. 
Männliche Patienten zeigten in jeder Subgruppe eine erhöhte Durchseuchungsrate mit hrHPV, während sich diese bei IrHPV etwa paritätisch bei beiden Geschlechtern verhielt.

Diese Ergebnisse waren jedoch nicht signifikant und zeigten nur einen Trend in unseren Beobachtungen (Abbildung 35).

Diese Abbildung ist aus urheberrechtlichen Gründen nicht in der Habilitationsschrift enthalten. Die Abbildung ist in der Autorenversion enthalten und kann über den Autor eingesehen werden.

Abbildung 35 - Korrelation von Geschlecht und HPV-Status in Spinalzellkarzinomen

Männliche Patienten zeigten in jeder Subgruppe eine erhöhte Durchseuchungsrate mit hrHPV, während sich diese bei IrHPV etwa paritätisch bei beiden Geschlechtern verhielt. Diese Ergebnisse waren jedoch nicht signfikant und zeigten nur einen Trend in unseren Beobachtungen

\subsubsection{Publikation}

Unpublizierte Daten. Arbeiten von Frau Rui Aoki, MD, PhD. (wissenschaftliche Mitarbeiterin von Herrn Prof. Dr. med. Dr. h.c. mult. T. Ruzicka und Herrn Dr. med. Markus Reinholz). 


\subsection{Diodenlaser in der Behandlung von Genitalwarzen}

2.6.1. Fragestellung: Welche Wirksamkeit hat der Diodenlaser in der Behandung von Genitalwarzen

\subsubsection{Projektdurchführung}

Die Infektion mit humanen Papillomaviren (HPVs) stellt die häufigste viral sexuell übertragbare Erkrankung dar. Im Rahmen dieser kann es zur Ausbildung von Genitalwarzen kommen. Die Entwicklung von Läsionen beginnt mit kleinen Flecken. Diese werden dann größer sowie vorspringend und verschmelzen schließlich zu Plaque-ähnlichen Formationen.

Ziel dieser Studie war es, die Wirksamkeit der Diodenlaserbehandlung für Genitalwarzen in Abhängigkeit von ihrer Anzahl und Größe hinsichtlich der Rezidivrate zu bewerten.

45 Patienten mit Condylomata acuminata wurden nach einer Behandlung nach dem Studienprotokoll mit dem Dornier MedTech Medilas ${ }^{\circledR}$ D Diodenlaser (Dornier MedTech $\mathrm{GmbH}$; Weßling; Deutschland) ausgewertet.

Die eingeschlossenen Patienten wurden je nach Größe und Anzahl ihrer Genitalwarzen einer von zwei Gruppen im Voraus zugeordnet. Patienten mit maximal 20 einzelnstehenden Warzen von bis zu $7 \mathrm{~mm} \times 7 \mathrm{~mm}$ wurden in Gruppe I (25 Patienten) aufgenommen und in einer Lasersitzung behandelt. Patienten mit mehr als 20 Warzen, größerer Infektionsfläche oder koaleszenten Warzen wurden in Gruppe II (20 Patienten) mit zwei Lasersitzungen randomisiert. Neben der Größe und Anzahl wurde auch die Lokalisation erfasst. Zusätzlich wurden die Heilungsrate und der Prozentsatz der Rückfälle im Zeitabstand von drei Monaten dokumentiert, wobei zwischen lokoregionalen Rückfällen und neuen Formationen unterschieden wurde (Tabelle 8).

Diese Tabelle ist aus urheberrechtlichen Gründen nicht in der Habilitationsschrift enthalten. Die Tabelle ist in der Autorenversion enthalten und kann über den Autor eingesehen werden. 
Diese Tabelle ist aus urheberrechtlichen Gründen nicht in der Habilitationsschrift enthalten. Die

Tabelle ist in der Autorenversion enthalten und kann über den Autor eingesehen werden.

Tabelle 8 - Übersicht der teilnehmenden Patienten

\section{Ergebnisse}

In der Gruppe I wurden 21 von 25 Patienten nach 3 Monaten geheilt (letztes Follow-up), was eine Heilungsrate von $84 \%$ ergab. In Gruppe II war die Heilungsrate nach der ersten Sitzung $25 \%$, nach der zweiten Sitzung weitere 35\%, insgesamt 60\% (12 von 20 Patienten). Summarisch wurde eine Heilungsrate von 73,3\% erreicht (33 von 45 Patienten) (Tabelle 9).

Diese Tabelle ist aus urheberrechtlichen Gründen nicht in der Habilitationsschrift enthalten. Die Tabelle ist in der Autorenversion enthalten und kann über den Autor eingesehen werden.

Tabelle 9 - Heilungsraten

In der Gruppe I wurden 21 von 25 Patienten nach 3 Monaten geheilt (letztes Follow-up), was eine Heilungsrate von $84 \%$ ergab. In Gruppe II war die Heilungsrate nach der ersten Sitzung 25\%, nach der zweiten Sitzung weitere 35\%, insgesamt $60 \%$ (12 von 20 Patienten). Summarisch wurde eine Heilungsrate von $73,3 \%$ erreicht (33 von 45 Patienten).

Die Heilungsrate gab den Prozentsatz beziehungsweise die Anzahl der Patienten wieder, die mindestens drei Monate nach der Laserbehandlung klinisch symptomfrei waren.

Diese Abbildung ist aus urheberrechtlichen Gründen nicht in der Habilitationsschrift enthalten. Die Abbildung ist in der Autorenversion enthalten und kann über den Autor eingesehen werden.

Abbildung 36 - Heilungsraten in den jeweiligen Gruppen nach zwei Laserungen

In der Gruppe I wurden 21 von 25 Patienten nach 3 Monaten geheilt (letztes Follow-up), was eine Heilungsrate von 84\% ergab. In Gruppe II war die Heilungsrate nach der ersten Sitzung $25 \%$, nach der zweiten Sitzung weitere $35 \%$, insgesamt $60 \%$ (12 von 20 Patienten). Summarisch wurde eine Heilungsrate von 73,3\% erreicht (33 von 45 Patienten). Vergleiche Tabelle 9. 
Tabelle 9 und Abbildung 37 zeigen deutliche Unterschiede zwischen den Gruppen in Bezug auf die Heilungsrate nach zwei Laserungen, die Anzahl der Laserbehandlungen bis zur Beseitigung aller Kondylome und dem Wiederauftreten von Kondylomen.

Neubildungen traten häufiger auf als echte Rezidive. Von den 10 Fällen, in denen wieder Kondylome auftraten, waren $60 \%$ neue Kondylome an bisher unbehandelten Stellen und nur $40 \%$ echte Rezidive. Es gab keinen signifikanten Unterschied zwischen Gruppe I und II bezüglich neue Kondylome und Rezidive (Abbildung 38).

Diese Abbildung ist aus urheberrechtlichen Gründen nicht in der Habilitationsschrift enthalten. Die Abbildung ist in der Autorenversion enthalten und kann über den Autor eingesehen werden.

Abbildung 37 - Aufteilung der „Rezidive“

Neubildungen traten häufiger auf als echte Rezidive. Von den 10 Fällen, in denen wieder Kondylome auftraten, waren $60 \%$ neue Kondylome an bisher unbehandelten Stellen und nur $40 \%$ echte Rezidive. 


\section{Zusammenfassung}

Zusammenfassend handelte es sich bei Condylomata acuminata um eine, trotz multipler zugelassener und experimenteller Therapien, durchaus schwer zu therapierende Erkrankung. Die Lebensqualität der Betroffenen ist stark eingeschränkt. Die Ansteckungsgefahr von HPV ist beträchtlich, was zu einer entsprechenden Durchseuchungsrate in der Bevölkerung führt. Weiterhin ist eine Entartung möglich. Die Therapien sind langwierig und von mäßigem Erfolg gekennzeichnet. Condylomata acuminata weisen hohe Rezidivraten auf. Die Abheilungs- und Rezidivquote der Therapiemethoden unterscheiden sich. Betrachtet man beide Quoten zusammen, hebt sich keine Behandlungsform hervor. Nebenwirkungen treten bei allen Behandlungen auf. Diese reichen von vor allem Hautirritationen bei den konservativen Methoden, wie der Imiquimod oder Podophyllinanwendung, bis hin zu Vernarbungen und postoperativen Beschwerden bei den chirurgischen Methoden mit Skalpell, Kryotherapie oder Laseranwendungen.

In dieser Studie wurde die erfolgreiche Anwendung des Diodenlasers als Therapiemöglichkeit in Bezug auf Verträglichkeit und Rezidivrisiko bei Condylomata acuminata gezeigt.

Schlussfolgerungen

Durch die Aufteilung der Laserbehandlung bei mehrfachen, umfangreichen oder koaleszierenden Genitalwarzen in zwei Behandlungssitzungen, konnten vergleichbare Heilungsraten zwischen den beiden Gruppen erreicht werden. Durch die Laserung wurde das umliegende Gewebe zudem geschont. Im Allgemeinen war die Laserbehandlung genauso effektiv wie andere topische oder chirurgische Behandlungsmöglichkeiten.

\subsubsection{Publikation}

Unpublizierte Daten. Doktorarbeit Frau Schinack-Kühne (Doktorvater: Prof. Dr. med. Kaudewitz; mitbetreuender wissenschaftlicher Mitarbeiter: Dr. med. Markus Reinholz). 


\section{Zusammenfassung und Ausblick}

Die dargestellten Forschungsarbeiten sollten zu einem verbesserten Verständnis der HPV-Infektion führen. Dabei stand zunächst vorrangig die angeborene Immunität im Fokus.

Im Verlauf sollten durch die epidemiologischen Studien ein exakteres Risikoprofil von HPV-Patienten mit anschließend zielgerichteteren Awareness-Kampagnen durch beispielsweise die BzgA erfolgen.

Weiterhin wurden die Anwendbarkeit und die Vorteile einer physikalischen Behandlung von Feigwarzen mittels Diodenlasers gezeigt. Dies kann möglicherweise in der Zukunft zur Etablierung einer schonenderen Eradikations-Behandlung führen.

Die dargestellte Forschung hat zum Ziel, die HPV-Infektion als häufigste virale sexuell übertragbare Erkrankung besser zu verstehen, Betroffene zu identifizieren, HPVInfektionen leichter zu diagnostizieren und bessere Behandlungsregime zu entwickeln. 


\section{Literatur}

1. Abramowitz, L., et al., Anal squamous intraepithelial lesions and condyloma in HIVinfected heterosexual men, homosexual men and women: prevalence and associated factors. AIDS, 2007. 21(11): p. 1457-65.

2. Arron, S.T., et al., Viral oncogenesis and its role in nonmelanoma skin cancer. $\mathrm{Br} \mathrm{J}$ Dermatol, 2011. 164(6): p. 1201-13.

3. Arron, S.T., et al., Transcriptome sequencing demonstrates that human papillomavirus is not active in cutaneous squamous cell carcinoma. J Invest Dermatol, 2011. 131(8): p. 1745-53.

4. Asgari, M.M., et al., Detection of human papillomavirus DNA in cutaneous squamous cell carcinoma among immunocompetent individuals. J Invest Dermatol, 2008. 128(6): p. 1409-17.

5. Berkhout, R.J., et al., Nested PCR approach for detection and typing of epidermodysplasia verruciformis-associated human papillomavirus types in cutaneous cancers from renal transplant recipients. J Clin Microbiol, 1995. 33(3): p. 690-5.

6. Bishop, P.E., A. McMillan, and S. Fletcher, An immunohistological study of spontaneous regression of condylomata acuminata. Genitourin Med, 1990. 66(2): p. 79-81.

7. Bosch, F.X., et al., Prevalence of human papillomavirus in cervical cancer: a worldwide perspective. International biological study on cervical cancer (IBSCC) Study Group. J Natl Cancer Inst, 1995. 87(11): p. 796-802.

8. Cardoso, J.C. and E. Calonje, Cutaneous manifestations of human papillomaviruses: a review. Acta Dermatovenerol Alp Pannonica Adriat, 2011. 20(3): p. 145-54.

9. Chahoud, J., et al., Association between beta-genus human papillomavirus and cutaneous squamous cell carcinoma in immunocompetent individuals-a metaanalysis. JAMA Dermatol, 2016. 152(12): p. 1354-1364.

10. Coleman, N., et al., Immunological events in regressing genital warts. Am J Clin Pathol, 1994. 102(6): p. 768-74.

11. Dalla Pria, A., et al., High-resolution anoscopy screening of HIV-positive MSM: longitudinal results from a pilot study. AIDS, 2014. 28(6): p. 861-7.

12. de Villiers, E.M., Cross-roads in the classification of papillomaviruses. Virology, 2013. 445(1-2): p. 2-10.

13. Dietrich, A., et al., Human papillomavirus status, anal cytology and histopathological outcome in HIV-positive patients. J Eur Acad Dermatol Venereol, 2015. 29(10): p. 2011-8.

14. Doorbar, J., Molecular biology of human papillomavirus infection and cervical cancer. Clin Sci (Lond), 2006. 110(5): p. 525-41.

15. Doorbar, J., et al., Human papillomavirus molecular biology and disease association. Rev Med Virol, 2015. 25 Suppl 1: p. 2-23.

16. Dyson, N., et al., The human papilloma virus-16 E7 oncoprotein is able to bind to the retinoblastoma gene product. Science, 1989. 243(4893): p. 934-7.

17. Eitel, J., N. Suttorp, and B. Opitz, Innate immune recognition and inflammasome activation in listeria monocytogenes infection. Front Microbiol, 2010. 1: p. 149.

18. Esser, S., DAIG-Leitlinie: Anale Dysplasien und Analkarzinome bei HIV-Infizierten: Prävention, Diagnostik und Therapie. AWMF, 2013.

19. Fernandes-Alnemri, T., et al., The pyroptosome: a supramolecular assembly of ASC dimers mediating inflammatory cell death via caspase-1 activation. Cell Death Differ, 2007. 14(9): p. 1590-604.

20. Fink, S.L. and B.T. Cookson, Apoptosis, pyroptosis, and necrosis: mechanistic description of dead and dying eukaryotic cells. Infect Immun, 2005. 73(4): p. 1907-16.

21. Freitas, A.C., et al., Human papillomavirus vertical transmission: review of current data. Clin Infect Dis, 2013. 56(10): p. 1451-6. 
22. Frisch, M., R.J. Biggar, and J.J. Goedert, Human papillomavirus-associated cancers in patients with human immunodeficiency virus infection and acquired immunodeficiency syndrome. J Natl Cancer Inst, 2000. 92(18): p. 1500-10.

23. Frisch, M., et al., Sexually transmitted infection as a cause of anal cancer. N Engl J Med, 1997. 337(19): p. 1350-8.

24. Gervaz, P., B. Hirschel, and P. Morel, Molecular biology of squamous cell carcinoma of the anus. Br J Surg, 2006. 93(5): p. 531-8.

25. Goedert, J.J., et al., Spectrum of AIDS-associated malignant disorders. Lancet, 1998. 351(9119): p. 1833-9.

26. Graham, S.V., Human papillomavirus: gene expression, regulation and prospects for novel diagnostic methods and antiviral therapies. Future Microbiol, 2010. 5(10): p. 1493-506.

27. Gross, G., Genitoanal human papillomavirus infection and associated neoplasias. Curr Probl Dermatol, 2014. 45: p. 98-122.

28. Gross, G., et al., Vaccination against HPV-Associated Neoplasias: Recommendations from the Current S3 Guideline of the HPV Management Forum of the Paul-Ehrlich Society - AWMF Guidelines, Registry No. 082-002 (short version), valid until Dec. 31st, 2018. Geburtshilfe Frauenheilkd, 2014. 74(3): p. 233-241.

29. Hornung, V., et al., AIM2 recognizes cytosolic dsDNA and forms a caspase-1activating inflammasome with ASC. Nature, 2009. 458(7237): p. 514-8.

30. Iftner, A., et al., The prevalence of human papillomavirus genotypes in nonmelanoma skin cancers of nonimmunosuppressed individuals identifies high-risk genital types as possible risk factors. Cancer Res, 2003. 63(21): p. 7515-9.

31. Kremsdorf, D., et al., Molecular cloning and characterization of the genomes of nine newly recognized human papillomavirus types associated with epidermodysplasia verruciformis. J Virol, 1984. 52(3): p. 1013-8.

32. Kreuter, A., et al., [Screening and therapy of anal intraepithelial neoplasia (AIN) and anal carcinoma in patients with HIV-infection]. Dtsch Med Wochenschr, 2003. 128(38): p. 1957-62.

33. Lacey, C.J., et al., 2012 European guideline for the management of anogenital warts. J Eur Acad Dermatol Venereol, 2013. 27(3): p. e263-70.

34. Mariathasan, S. and D.M. Monack, Inflammasome adaptors and sensors: intracellular regulators of infection and inflammation. Nat Rev Immunol, 2007. 7(1): p. 31-40.

35. Melbye, M., et al., High incidence of anal cancer among AIDS patients. The AIDS/Cancer Working Group. Lancet, 1994. 343(8898): p. 636-9.

36. Moody, C.A. and L.A. Laimins, Human papillomavirus oncoproteins: pathways to transformation. Nat Rev Cancer, 2010. 10(8): p. 550-60.

37. Mosthaf, F.A., et al., [High incidence of non-AIDS-defined cancers among HIVinfected patients in Germany. A 3-year nationwide review]. Dtsch Med Wochenschr, 2006. 131(34-35): p. 1849-52.

38. Palefsky, J.M., et al., Prevalence and risk factors for anal human papillomavirus infection in human immunodeficiency virus (HIV)-positive and high-risk HIV-negative women. J Infect Dis, 2001. 183(3): p. 383-91.

39. Park, I.U., C. Introcaso, and E.F. Dunne, Human Papillomavirus and Genital Warts: A Review of the Evidence for the 2015 Centers for Disease Control and Prevention Sexually Transmitted Diseases Treatment Guidelines. Clin Infect Dis, 2015. 61 Suppl 8: p. S849-55.

40. Pett, M.R., et al., Acquisition of high-level chromosomal instability is associated with integration of human papillomavirus type 16 in cervical keratinocytes. Cancer Res, 2004. 64(4): p. 1359-68.

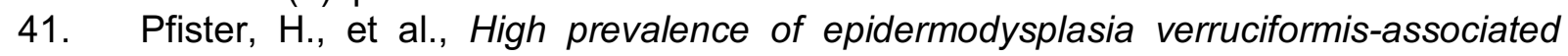
human papillomavirus DNA in actinic keratoses of the immunocompetent population. Arch Dermatol Res, 2003. 295(7): p. 273-9.

42. Pierceall, W.E., L.H. Goldberg, and H.N. Ananthaswamy, Presence of human papilloma virus type 16 DNA sequences in human nonmelanoma skin cancers. J Invest Dermatol, 1991. 97(5): p. 880-4. 
43. Prevention, C.f.D.C.a. HPV - Sexually Transmitted Diseases Treatment Guidelines 2015 [cited 2016 28.12.2016].

44. Quereux, G., J.M. N'Guyen, and B. Dreno, Human papillomavirus and extragenital in situ carcinoma. Dermatology, 2004. 209(1): p. 40-5.

45. Reinholz, M., et al., HPV16 activates the AIM2 inflammasome in keratinocytes. Arch Dermatol Res, 2013. 305(8): p. 723-32.

46. Rosales, R. and C. Rosales, Immune therapy for human papillomaviruses-related cancers. World J Clin Oncol, 2014. 5(5): p. 1002-19.

47. Scheffner, M., et al., The E6 oncoprotein encoded by human papillomavirus types 16 and 18 promotes the degradation of p53. Cell, 1990. 63(6): p. 1129-36.

48. Shi, J., W. Gao, and F. Shao, Pyroptosis: Gasdermin-Mediated Programmed Necrotic Cell Death. Trends Biochem Sci, 2016.

49. Sobhani, I., et al., Prevalence of high-grade dysplasia and cancer in the anal canal in human papillomavirus-infected individuals. Gastroenterology, 2001. 120(4): p. 85766.

50. Stanley, M., Immune responses to human papillomavirus. Vaccine, 2006. 24 Suppl 1: p. S16-22.

51. Stanley, M.A., Epithelial cell responses to infection with human papillomavirus. Clin Microbiol Rev, 2012. 25(2): p. 215-22.

52. Stanley, M.A., Immune responses to human papilloma viruses. Indian J Med Res, 2009. 130(3): p. 266-76.

53. Syrjanen, S., The role of human papillomavirus infection in head and neck cancers. Ann Oncol, 2010. 21 Suppl 7: p. vii243-5.

54. Wang, J., et al., Role of human papillomavirus in cutaneous squamous cell carcinoma: a meta-analysis. J Am Acad Dermatol, 2014. 70(4): p. 621-9.

55. Weissenborn, S.J., et al., Human papillomavirus-DNA loads in actinic keratoses exceed those in non-melanoma skin cancers. J Invest Dermatol, 2005. 125(1): p. 937.

56. Wen, H., E.A. Miao, and J.P. Ting, Mechanisms of NOD-like receptor-associated inflammasome activation. Immunity, 2013. 39(3): p. 432-41.

57. Wentzensen, N., et al., Eurogin 2016 Roadmap: How HPV knowledge is changing screening practice. Int J Cancer, 2016.

58. White, M.K., J.S. Pagano, and K. Khalili, Viruses and human cancers: a long road of discovery of molecular paradigms. Clin Microbiol Rev, 2014. 27(3): p. 463-81.

59. Wilkins, C. and M. Gale, Jr., Recognition of viruses by cytoplasmic sensors. Curr Opin Immunol, 2010. 22(1): p. 41-7.

60. Zheng, S., et al., Human papillomaviruses of the mucosal type are present in some cases of extragenital Bowen's disease. Br J Dermatol, 2005. 152(6): p. 1243-7.

61. zur Hausen, H., Papillomaviruses in the causation of human cancers - a brief historical account. Virology, 2009. 384(2): p. 260-5. 


\section{Publikationsliste (Stand November 2017)}

\subsection{Originalarbeiten als Erst- oder Letztautor}

1. Reinholz M, Schwaiger H, Poetschke J, Epple A, Ruzicka T, von Braunmühl T, Gauglitz GG

Objective and subjective treatment evaluation of scars using optical coherence tomography, sonography, photography, and standardised questionnaires Eur J Dermatol. 2016 Dec 1;26(6):599-608. doi: 10.1684/ejd.2016.2873. IF (2013): 1.953

2. Poetschke $J^{*}$, Reinholz $\mathbf{M}^{*}$, Schwaiger $H$, Epple A, Gauglitz GG. DLQI and POSAS scores in keloid patients.

Facial Plast Surg. 2016 Jun;32(3):289-95. doi: 10.1055/s-0036-1583851. Epub 2016 Jun 1. IF (2013): 0.992

3. Reinholz M, Schwaiger H, Heppt MV, Poetschke J, Tietze J, Epple A, Ruzicka T, Kaudewitz P, Gauglitz GG.

Comparison of two kinds of lasers in the treatment of acne scars.

Facial Plast Surg. 2015 Oct;31(5):523-31.

IF (2013): 0.992

4. Dietrich A, Hermans C, Heppt MV, Ruzicka T, Schauber J, Reinholz M

Human papillomavirus status, anal cytology and histopathological outcome in HIVpositive patients

J Eur Acad Dermatol Venereol. 2015 Oct;29(10):2011-8. doi: 10.1111/jdv.13205.

Epub 2015 Aug 14.

IF( 2013): 3.105

5. Reinholz M, Poetschke J, Schwaiger H, Epple A, Ruzicka T, Gauglitz GG.

The dermatology life quality index as a means to assess life quality in patients with different scar types.

J Eur Acad Dermatol Venereol. 2015 Apr 10. doi: 10.1111/jdv.13135.

IF( 2013): 3.105

6. Reinholz M, Gauglitz GG, Giehl K, Braun-Falco M, Schwaiger H, Schauber J, Ruzicka T, Berneburg M, von Braunmühl T

Non-invasive diagnosis of sweat gland dysplasia using optical coherence tomography and reflectance confocal microscopy in a family with anhidrotic ectodermal dysplasia (Christ-Siemens-Touraine syndrome).

J Eur Acad Dermatol Venereol. 2015 Mar 9. doi: 10.1111/jdv.13085.

IF( 2013): 3.105

7. Reinholz M, Kawakami Y, Salzer S, Kreuter A, Dombrowski Y, Koglin S, Kresse S, Ruzicka T, Schauber J.

HPV16 activates the AIM2 inflammasome in keratinocytes.

Arch Dermatol Res. 2013 Oct;305(8):723-32.

IF (2013): 2.270 


\subsection{Originalarbeiten als Co-Autor}

1. Guertler A, Reinholz M, Poetschke J, Steckmeier S, Schwaiger H, Gauglitz GG. Objective evaluation of the efficacy of a non-ablative fractional $1565 \mathrm{~nm}$ laser for the treatment of deliberate self-harm scars.

Lasers Med Sci. 2017 Oct 27. doi: 10.1007/s10103-017-2348-x.

IF (2016): 2.299

2. Poetschke J, Dornseifer U, Clementoni MT, Reinholz M, Schwaiger H, Steckmeier S, Ruzicka T, Gauglitz GG.

Ultrapulsed fractional ablative carbon dioxide laser treatment of hypertrophic burn scars: evaluation of an in-patient controlled, standardized treatment approach. Lasers Med Sci. 2017 Jul;32(5):1031-1040. doi: 10.1007/s10103-017-2204-z. Epub 2017 Apr 12.

IF (2016): 2.299

3. Tietze JK, Angelova D, Heppt MV, Reinholz M, Murphy WJ, Spannagl M, Ruzicka T, Berking $\mathrm{C}$.

The proportion of circulating CD45RO+CD8+ memory $T$ cells is correlated with clinical response in melanoma patients treated with ipilimumab.

Eur J Cancer. 2017 Feb 24;75:268-279. doi: 10.1016/j.ejca.2016.12.031. IF (2014): 5.417

4. Heppt MV, Tietze JK, Reinholz M, Rahimi F, Jung A, Kirchner T, Ruzicka T, Flaig MJ, Berking C.

Disease kinetics but not disease burden is relevant for survival in melanoma of unknown primary tumor.

Discov Med. 2015 Oct;20(110):231-7.

IF (2014): 3.626

5. Heppt MV, Breuninger H, Reinholz M, Feller-Heppt G, Ruzicka T, Gauglitz GG. Current strategies in the treatment of scars and keloids.

Facial Plast Surg. 2015 Aug;31(4):386-95. doi: 10.1055/s-0035-1563694. Epub 2015

Sep 15.

IF (2013): 0.992

6. Heppt MV, Reinholz M, Tietze JK, Kerl K, French LE, Berking C, Kamarashev J. Clinicopathologic features of primary cutaneous melanoma: a single centre analysis of a Swiss regional population.

Eur J Dermatol. 2015 Mar 17. Eur J Dermatol. 2015 Apr;25(2):127-32. IF (2013): 1.953

7. Salzer S, Kresse S, Hirai Y, Koglin S, Reinholz M, Ruzicka T, Schauber J. Cathelicidin peptide LL-37 increases UVB-triggered inflammasome activation: Possible implications for rosacea.

J Dermatol Sci. 2014 Sep 28. doi: 10.1016/j.jdermsci.2014.09.002.

IF (2013): 3.335

8. Ehmann L, Reinholz M, Maier T, Lang M, Wollenberg A.

Toleriane fluid efficacy in perioral dermatitis- results of the TOLPOD study. Ann Dermatol. 2014 Aug;26(4):462-8.

IF (2013): 0.954 
9. Dombrowski Y, Peric M, Koglin S, Kaymakanov N, Schmezer V, Reinholz M, Ruzicka $\mathrm{T}$, Schauber J.

Honey bee (Apis mellifera) venom induces AIM2 inflammasome activation in human keratinocytes .

Allergy. 2012 Nov;67(11):1400-7.

IF (2012): 5.883

10. Zhou Z, Subramanian P, Sevilmis G, Globke B, Soehnlein O, Karshovska E, Megens R, Heyll K, Chun J, Saulnier-Blache JS, Reinholz M, van Zandvoort M, Weber C, Schober A.

Lipoprotein-derived lysophosphatidic acid promotes atherosclerosis by releasing CXCL1 from the endothelium.

Cell Metab 2011;13:592-600.

IF (2011): 13.668 


\subsection{Kasuistiken/Case Reports}

1. Reinholz M, Heppt MV, Hoffmann FS, Lummel N, Ruzicka T, Lehmann P, Berking C. Transient memory impairment and transient global amnesia induced by photodynamic therapy.

Br J Dermatol. 2015 Nov;173(5):1258-62. doi: 10.1111/bjd.13985. Epub 2015 Oct 5. IF(2013): 4.100

2. Reinholz M, Eder I, Przybilla B, Schauber J, Ruzicka T, Schaumann A, Goldscheider I, Varga $R$, Wollenberg A, Schauber J, Wulffen W, Ruëff $F$ Photoallergic contact dermatitis due to treatment of pulmonary fibrosis with pirfenidone J Eur Acad Dermatol Venereol. 2014 Oct 20. doi: 10.1111/jdv.12794.

IF( 2013): 3.105

3. Gauglitz GG, Reinholz M, Kaudewitz P, Schauber J, Ruzicka T.

Treatment of striae distensae using an ablative Erbium: YAG fractional laser versus a $585-\mathrm{nm}$ pulsed-dye laser.

J Cosmet Laser Ther. 2014 Jun;16(3):117-9. doi: 10.3109/14764172.2013.854621. Epub 2013 Nov 18.

IF (2013): 1.110 


\section{4. Übersichtsartikel/Reviews}

1. Reinholz M, Ruzicka T, Steinhoff M, Schaller M, Gieler U, Schöfer H, Homey B, Lehmann P, Luger TA.

Pathogenese und Klinik der Rosazea als Schlüssel für eine symptomorientierte Therapie. J Dtsch Dermatol Ges. 2016 Dec;14 Suppl 6:4-16. doi: 10.1111/ddg.13139_g.

IF (2013): 1.815

2. Reinholz M, Hermans C, Ruzicka T, Dietrich A.

[Anogenital diseases caused by human papillomavirus - A modern pandemia].

MMW Fortschr Med. 2016 Mar;158(5):64-7. doi: 10.1007/s15006-016-7946-1. German.

IF (2013): 0,00

3. Heppt M, Hartmann D, Reinholz M, Feller-Heppt G, Ruzicka T, Gauglitz GG.

[Fillers and associated side effects].

HNO. 2015 Jul;63(7):472-80. doi: 10.1007/s00106-015-0030-9.

IF (2013): 0.53

4. Reinholz M, Kilian K, Kloevekorn W, Lehmann P, Meigel EM, Ruzicka T, Schaller M, Schoefer H, Tietze J, Zierhut M, Schauber J.

S1-Leitlinie der Deutschen Dermatologischen Gesellschaft - Rosazea.

J Dtsch Dermatol Ges. 2013 Aug;11(8):768-80; 768-79.

IF (2013): 1.815

5. Reinholz M, Kaudewitz P.

Hautzeichen bei internistischen Erkrankungen.

Der Bayerische Internist; Heft 3 / Juli 2013

6. Reinholz M, Schauber J.

Vitamin $\mathrm{D}$ und die angeborene Immunität der Haut.

Deut Med Wochenschr. 2012 Nov;137(46):2385-9.

IF (2012): 0.653

7. Reinholz M, Ruzicka T, Schauber J.

Vitamin $D$ and its role in allergic disease.

Clin Exp Allergy. 2012 Jun;42(6):817-26. doi: 10.1111/j.1365-2222.2011.03923.x.

IF (2012): 4.789

8. Reinholz M, Ruzicka T, Schauber J.

Cathelicidin LL-37: An antimicrobial peptide with a role in inflammatory skin disease.

Ann Dermatol 2012 May; 24(2): 126-135

IF (2012): 0.611 


\subsection{Buchkapitel/Book Chapters}

1. Poetschke J, Reinholz M, Gauglitz G Medical Management of Scars · January 2017

In book: The Scar Book: Formation, Mitigation, Rehabilitation, and Prevention, Publisher: Wolters Kluwer, Editors: Andrew C. Krakowski, Peter R. Shumaker

2. Wollenberg A, Reinholz M

Kapitel: Haut und Knochen.

Bartl R (Hrsg.) Osteologie. Thieme, Stuttgart. ISBN 978-3-13-170161-9

\subsection{Sonstige Veröffentlichungen (z. B. Letters to the Editor)}

1. Ruini C, Sattler E, Hartmann D, Reinholz M, Ruzicka T, von Braunmühl T. Monitoring structural changes in Demodex mites under topical Ivermectin in rosacea by means of reflectance confocal microscopy: a case series.

J Eur Acad Dermatol Venereol. 2017 Jun;31(6):e299-e301. doi: 10.1111/jdv.14084. IF( 2013): 3.105

2. Käser S, Ruini C, Ezmerli M, Braunmühl TV, Hartmann D, Ruzicka T, Reinholz M EGFRI-induced papulopustular rosacea-like rash successfully treated with topical ivermectin. J Eur Acad Dermatol Venereol. 2016 Dec 18. doi: 10.1111/jdv.14089. [Epub ahead of print] IF( 2013): 3.105

3. Reinholz M, Heppt M, Tietze JK, Ruzicka T, Gauglitz GG, Schauber J.

Photoletter to the editor: Topical $0.5 \%$ brimonidine gel to camouflage redness of immature scars.

J Dermatol Case Rep. 2015 Sep 30

IF (2013): 0,00

4. Reinholz M, Hermans C, Dietrich A, Ruzicka T, Braun-Falco M.

A case of cutaneous vegetating candidiasis in a patient with Keratitis-Ichthyosis-Deafness Syndrome.

J Eur Acad Dermatol Venereol. 2015 Jan 20. doi: 10.1111/jdv.12936. [Epub ahead of print] IF( 2013): 3.105

5. Reinholz M, Berking C, Ruzicka T, Braun-Falco M

Eruption of Lupus erythematosus during Vemurafenib therapy

J Am Acad Dermatol. 2014 Oct;71(4):e159-60. doi: 10.1016/j.jaad.2014.07.006. No abstract available.

IF(2013): 5.004

6. Reinholz M

A peptide from a gastric pathogen for the treatment of acne.

Br J Dermatol. 2014 Dec;171(6):1291. doi: 10.1111/bjd.13458.

IF(2013): 4.100

7. Reinholz M, Ruzicka T

Darwin as a dermatologist.

JAMA Dermatology 2014;150(6):600. doi:10.1001/jamadermatol.2013.10439

IF (2013): 4.792 


\subsection{Zulassungsstudien}

1. Efficacy and safety of CD5024 1\% cream versus metronidazole $0,75 \%$ cream in subjects with papulopustular rosacea over 16 weeks treatment, followed by a 36-week extension period (RD.03.SPR.40173); study coordinator, subinvestigator

2. Doppelblinde, randomisierte, Vehikel-kontrollierte, multizentrische Dosisfindungsstudie zur Bewertung von Sicherheit, Verträglichkeit, Wirksamkeit und Pharmakokinetik von topischen Neramexane bei Patienten mit mittelschwerer bis schwerer Akne (MUS92579_2057_1); subinvestigator

3. A Pediatric Longitudinal Evaluation to Assess the Long-Term Safety of Protopic for the Treatment of Atopic Dermatitis (APPLES), NCT00475605; subinvestigator

4. Prospektive, intra-individuell randomisierte, beobachterverblindete, kontrollierte Prüfung: OIP MRZ90011_0028_3; subinvestigator

Kumulative Impact-Punkte (Originalarbeiten/Übersichten; Stand 07.11.2017)

Gesamt

97,687

Erst-/Seniorautorschaften

49,411

Zitierungen

330

$\mathrm{H}$-Index

$\mathrm{H}$-Index (ohne Selbstzitierungen)
7

7 


\section{Abbildungsverzeichnis}

Abbildung 1 - Infektionsmodell und Virusreplikation von HPV .......................................

Abbildung 2 - Schematischer Aufbau des Inflammasoms ................................................4

Abbildung 3 - AIM2, IL-1 $\beta$ und Caspase-1 in AIN 3 bei HIV-positiven Patienten.....................7

Abbildung 4 - Expression von IFI16 in HPV-infizierter Haut ............................................

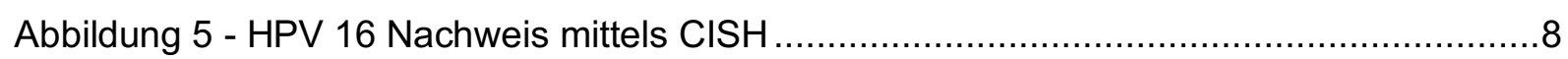

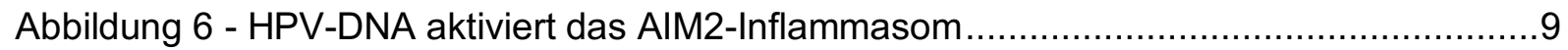

Abbildung 7 - Schema: Mögliche Interaktion zwischen dem IFI16- und AIM2-Signalweg......10

Abbildung 8 - Interaktion IFI16 und AIM2-Signalweg durch HPV-DNA .............................11

Abbildung 9 - Geschlechterverteilung der untersuchten HIV-Patienten..............................15

Abbildung 10 - Altersverteilung der untersuchten HIV-Patienten ..................................... 16

Abbildung 11 - Verteilung der HIV-Infektion in der Kohorte.........................................17

Abbildung 12 - Lokalisation der Gewebeproben ............................................................ 18

Abbildung 13 - Histologische Klassifizierung .............................................................19

Abbildung 14 - Histologie im Vergleich zur molekulargenetischen Analyse.........................21

Abbildung 15 - Häufigkeitsverteilung Subtypen in Feigwarzen..........................................22

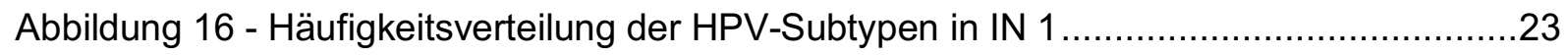

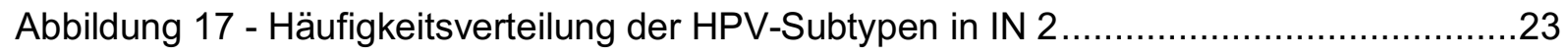

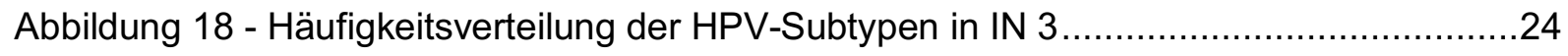

Abbildung 19 - Genitalwarze (Condyloma accuminatum) ...........................................26

Abbildung 20 - Verteilung der HPV-Patienten über den Beobachtungszeitraum ..................28

Abbildung 21 - Epidemiologische Verteilung der HPV-Infektion......................................30

Abbildung 22 - Dauer der symptomatischen Erkrankung ............................................. 31

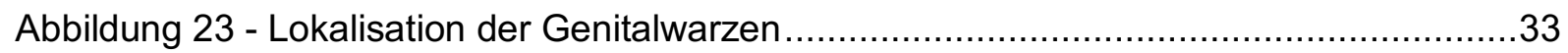

Abbildung 24 - Anzahl der Therapieversuche und Differenzierung der Therapien ................35

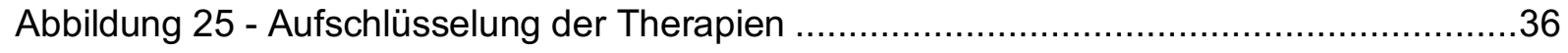

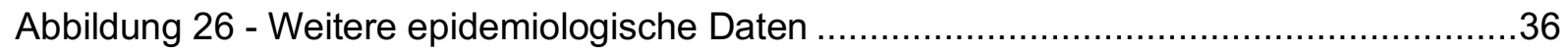

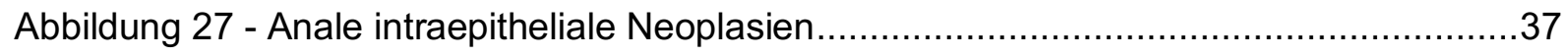

Abbildung 28 - Anzahl der jeweiligen Läsion .......................................................... 41

Abbildung 29 - Prozentualer Anteil von HPV-Subtypen in den Analzytologien .....................41

Abbildung 30 - Flußdiagramm bzgl. der Patientendiagnostik ........................................42

Abbildung 31 - Histologie im Vergleich zum zytologischen Befund (absolut) .......................43

Abbildung 32 - HPV-Subtypen in Spinalzellkarzinomen und aktinischen Keratosen .............48

Abbildung 33 - Korrelation zwischen UV-Exposition und HPV-Infektion in AKs und cuSCC .49

Abbildung 34 - Immunstatus und HPV bei Patienten mit Spinalzellkarzinomen ....................50

Abbildung 35 - Korrelation von Geschlecht und HPV-Status in Spinalzellkarzinomen...........51

Abbildung 37 - Heilungsraten in den jeweiligen Gruppen nach zwei Laserungen ................53 
Abbildung 38 - Aufteilung der "Rezidive“ .54 


\section{Tabellenverzeichnis}

1 - HPV-Subtypenkombinationen in IN verschiedener Schweregrade ....................20

2 - Histologie im Vergleich zur molekulargenetischen Analyse................................22

3 - Häufigkeitsverteilung Subtypen in Feigwarzen..............................................23

4 - Invasivitätsgrad und molekulargenetische Analyse von HPV 16 und HPV 18 ....24

5 - Demographie, klinische Charakteristik, HPV-Genotypisierung und Zytologie ......40

6 - Zusammenhang zwischen Zytologie und Histologie Dysplasiegrad ....................44

7 - Klinische Charakteristika der Patienten mit AKs und cuSCC ..........................47

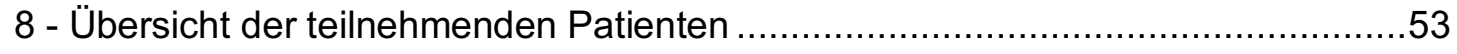

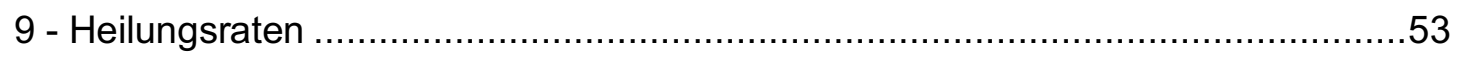




\section{Danksagung}

Ich danke Herrn Professor Thomas Ruzicka, Direktor der Klinik und Poliklinik für Dermatologie und Allergologie der Ludwig-Maximilians-Universität München und Herrn Professor Jürgen Schauber für die Überlassung des Themas und der Arbeitsmittel, die Gabe von entscheidenden Hinweisen zur Konzeption und die Gelegenheit zur Durchführung der Arbeit.

Mein Dank gilt darüber hinaus Herrn Professor Andreas Wollenberg, der diese Habilitation stets unterstützt hat und eine offene Atmosphäre des wissenschaftlichen Austausches und der Kooperation geschaffen hat. Ferner gilt mein Dank Herrn Professor Plewig und Frau Privatdozentin von Braunmühl für die Unterstützung und den wissenschaftlichen Austausch.

Weiterhin möchte ich Herrn Professor Stefan Endres und Frau Professor Carole Bourquin für die Einführung in das wissenschaftliche Arbeiten und die Begeisterung für die Wissenschaft danken.

Außerdem gilt mein Dank den Mitarbeitern meiner Arbeits- und Forschungsgruppe, insbesondere Herrn Benjamin Clanner-Engelshofen für seinen bereichernden, wissenschaftlichen Austausch, weiterhin Frau Sara Charnowski, Herrn Robert Cohen, Herrn Bruno Hundsdörfer, Frau Nicole Oeggl, Frau Dr. Rui Aoki, sowie Frau Nora Jøntvedt, ohne deren Unterstützung und Kreativität viele Teile dieser Arbeit nicht möglich gewesen wären.

Insbesondere möchte ich mich bei meiner Familie bedanken, die mich in vielen entscheidenden oder schwierigen Phasen geduldig und verständnisvoll unterstützt hat, mit dem oft notwendigen Verzicht auf eine gemeinsame Zeit; ohne sie an meiner Seite wäre diese Arbeit nicht möglich gewesen.

Mein Dank gilt nicht zuletzt den Patienten und Probanden, die bereit waren, an den Untersuchungen teilzunehmen. 


\section{Verwendung des Genus}

In dieser Arbeit wird das Genus zur Vereinfachung des Leseflusses in der männlichen Form angewandt. Es sind jedoch gleichberechtigt Frauen und Männer hiermit beschrieben.

\section{Abkürzungsverzeichnis} chromogene in situ-Hybridisierung

CTL

C-Typ-Lektin-Rezeptor

CuSCC kutanes Plattenepithelkarzinom DNA. ..Desoxyribonukleinsäure; kurz DNS; englisch DNA für deoxyribonucleic acid dsDNA. doppelsträngige DNA HIV Humanes Immunodefizienz-Virus

HPV Humane Papillomaviren Humanes Papillomavirus Subtyp 16 .. hochgradige Plattenepithel-Intraepithel-Läsion 
NALP NOD-like receptor

NHEKs. normalen, humane Keratinozyten / primären Keratinozyten

NILM zytologisch eingestufte negativ für intraepitheliale Läsion oder Malignität

NLR. NOD-like-Rezeptor

NLRC4 NLR family CARD domain-containing protein 4

NLRP1. .. NOD-like-Rezeptor containing protein 1

NLRP3. .. NOD-like-Rezeptor containing protein 1

PAMP. pathogen-associated molecular pattern

PIN. penile intraepitheliale Neoplasie PRR pattern-recognition receptors

PYCARD... PYRIN-PAAD-DAPIN domain (PYD); C-terminal caspase-recruitment domain (CARD) PYHIN . . pyrin and HIN-domain-containing protein RLR RIG-I-like-Rezeptor SCC. Spinalzellkarzinom

\section{SD} Standard deviation/Standardabweichung SiRNA small interfering RNA

TLR Toll-like Rezeptor TLR9. toll-like Rezeptor 9

VIN vulväre intraepitheliale Neoplasie $\alpha-H P V s$ Hoch-Risiko- $\alpha-$ Gattung menschliche Papillomaviren $\beta$-HPVs kutane $\beta$-Gattungs-HPVs 